\title{
Hidrodinâmica em zona de perturbação de barragem tropical
}

\section{Hydrodynamics in tropical dam disturbance zone}

\section{Hidrodinámica en zona de perturbación de embalse tropical}

\author{
Alesson Pires Maciel Guirra \\ http:/ / orcid.org/0000-0003-4201-3574 \\ engeoguirra@gmail.com \\ Universidade Federal dos Vales Jequitinhonha e Mucuri, Diamantina, MG
}

Jaíza Santos Motta

https:/ / orcid.org/0000-0002-3714-6631

ea.jsmotta@gmail.com

Universidade Federal de Mato Grosso do Sul, UFMS, Campo Grande, MS

Ariadne Barbosa Gonçalves

https:/ / orcid.org/0000-0003-2496-5723

ariadne.gon@gmail.com

Universidade Federal de Mato Grosso do Sul, UFMS, Campo Grande, MS

Antonio Conceição Paranhos Filho

https:/ / orcid.org/0000-0002-9838-5337

antonio.paranhos@pq.cnpq.br

Universidade Federal de Mato Grosso do Sul, UFMS, Campo Grande, MS

Resumo: A região de flutuação do nível da água em reservatórios representa uma zona de perturbação que experimenta exposição à inundação cíclica, devido suas operações, induzindo movimentos de massa marginais que se misturam ao constante transporte de sedimentos oriundos de bacias hidrográficas adjacentes. O objetivo deste estudo é determinar a melhor fonte de imagens multiespectrais de média resolução espacial para diagnosticar processos hidrodinâmicos, propondo uma chave de classificação baseada em composição de bandas de imagens de satélite. Além disso, entender quais os principais tipos de movimentos de massa ocorrem e como os fatores naturais e antrópicos condicionam estes eventos. Para isso, comparamos qualitativamente imagens dos satélites Landsat-5 TM, Landsat 8 OLI e Sentinel-2 MSI, em combinações de bandas simples e baseadas em equação com imagens detalhadas obtidas por aeronave remotamente pilotada. Verificamos que a associação entre a composição simples cor verdadeira 432 juntamente com a composição VRE-VIS, adaptada neste estudo, fornecem realces de transporte de sedimentos ativos em solo exposto nas 
margens do reservatório e a combinação VNIR-VRE2, também adaptada, apresenta melhor nitidez em relação à profundidade da lâmina d'água.

Palavras-chave: Usina Hidrelétrica, Reservatório Tropical, Perda de Solos, Sensoriamento Remoto.

\begin{abstract}
The region of water level fluctuation in reservoirs represents a disturbance zone that experiences exposure to cyclical flooding, due to its operations, inducing marginal mass movements that mix with the constant transport of sediments from adjacent hydrographic basins. The objective of this study is to determine the best source of multispectral images of medium spatial resolution to diagnose hydrodynamic processes, proposing a classification key based on the composition of satellite image bands. Besides, understand what the main types of mass movements occur and how natural and anthropic factors influence these events. For this, we qualitatively compare images from the Landsat-5 TM, Landsat 8 OLI, and Sentinel-2 MSI satellites, in combinations of simple bands and based on equation with detailed images obtained by remotely piloted aircraft. We found that the association between the simple composition true color 432 together with the composition VRE-VIS, adapted in this study, provides enhancements for transporting active sediments on exposed soil at the reservoir margins and the combination VNIR-VRE2, also adapted, presents better clarity concerning to the depth of the water depth.
\end{abstract}

Keywords: Hydroelectric Plant, Tropical Reservoir, Soil Loss, Remote Sensing.

Resumen: La región de fluctuación del nivel del agua en los embalses representa una zona de perturbación que experimenta exposición a inundaciones cíclicas, debido a sus operaciones, induciendo movimientos de masas marginales que se mezclan con el transporte constante de sedimentos de cuencas hidrográficas adyacentes. El objetivo de este estudio es determinar la mejor fuente de imágenes multiespectrales de resolución espacial media para diagnosticar procesos hidrodinámicos, proponiendo una clave de clasificación basada en la composición de bandas de imágenes satelitales. Además, comprender cuáles son los principales tipos de movimientos de masas que ocurren y cómo los factores naturales y antrópicos influyen en estos eventos. Para ello, comparamos cualitativamente imágenes de los satélites Landsat-5 TM, Landsat 8 OLI y Sentinel-2 MSI, en combinaciones de bandas simples y en base a ecuación con imágenes detalladas obtenidas por aeronaves pilotadas remotamente. Encontramos que la asociación entre la composición simple color verdadero 432 junto con la composición VRE-VIS, adaptada en este estudio, proporciona mejoras para el transporte de sedimentos activos en suelo expuesto en los márgenes del reservorio y la combinación VNIR-VRE2, también adaptada, presenta mejor claridad en relación a la profundidad del agua.

Palabras clave: Planta Hidroeléctrica, Embalse Tropical, Pérdida de Suelo, Detección Remota.

\title{
INTRODUÇÃO
}

O rio Paraná concentra um grande complexo hidroelétrico, onde a dinâmica fluvial perdeu características naturais ao ser controlado por algumas barragens. $\mathrm{O}$ sistema opera com ciclos de erosão e deposição constantes, extremamente dinâmicos e complexos 
devido a frequente transferência de energia no regime fluvial controlado por barragem. Os processos erosivos são intensificados e agravados em território com encostas íngremes e muito friáveis, oriundos do impacto de ondas com alturas significativas (Oliveira, 2004). Como os rios represados apresentam um alto potencial de acumulação de sedimentos de grãos finos, devido à exposição à forte erosão e a carga anômala de sedimento localizada a montante da barragem, aumenta-se deposição de fluxos de detritos na planície de inundação a jusante durante eventos catastróficos de escoamento (García, Sánchez, Navarro \& Pla, 2011).

As interações entre os processos geomorfológicos, hidrodinâmicos, geoquímicos e ecológicos fazem desta região uma unidade geomorfológica excepcional. Sendo assim, as análises multitemporais de imagens de satélite e pesquisa de campo contribuem para aprimorar o gerenciamento de reservatórios de usinas hidrelétricas (UHE) em cascata. Porém, há poucos estudos científicos sobre o impacto do represamento de água em erosão do solo, sendo que a maioria dos estudos ocorreu em regiões frias ou temperadas, com apenas alguns estudos em regiões tropicais (Bao et al., 2018).

Nesse contexto, este trabalho descreve e contextualiza impactos ambientais em zona de perturbação de reservatórios tropicais com o intuito de extrair informações qualitativas de dinâmica fluvial e de processos erosivos marginais. Inicialmente realizamos uma revisão na literatura sobre o contexto histórico de uso e ocupação do solo em regiões impactadas por barragens e como as geotecnologias vêm sendo aplicadas para diagnosticar estas áreas. Esta etapa é fundamental para que haja uma abordagem holística de processos erosivos, tendo em vista que estes são induzidos tanto por fatores naturais quanto antrópicos. $\mathrm{O}$ estudo também faz uso de geotecnologias em diferentes escalas espaciais e temporais a montante da barragem Porto Primavera, a qual contém o reservatório da UHE Engenheiro Sérgio Motta (UHEESM) com intuito de identificar qual dentre as técnicas de realce têm maior aplicabilidade para determinar locais onde operam processos erosivos marginais em reservatório, tendo em vista o detalhamento realizado em campo com aeronave remotamente pilotada. E por fim, elaboramos um perfil topográfico esquemático detalhando como os atributos do meio físico influenciam na deflagração de movimentos de massa nas margens do reservatório.

\section{ÁREA DE ESTUDO}

Com maior potencial hidrométrico do país, a porção brasileira da Bacia do Paraná conta com mais de 150 barragens hidrelétricas fazendo o rio Paraná e seus afluentes tornarem-se uma sucessão de lagos (Stevaux, Martins \& Meurer, 2009). Neste estudo foram selecionados cinco trechos a montante da barragem Porto Primavera, formador do reservatório UHEESM (Fig. 1). Esta é a barragem mais extensa do Brasil, interligando os Estados de Mato Grosso do Sul (MS) e São Paulo (SP), com 11.380,41 metros de largura total, incluindo as estruturas de terra e de concreto (Agência Nacional de Águas [ANA], 2014). O seu reservatório é considerado o quarto maior em área do Brasil $\left(2140 \mathrm{Km}^{2}\right)$, e o oitavo em capacidade volumétrica $\left(19,9 \mathrm{Km}^{3}\right)$, o que o enquadra na categoria de reservatório 
médio (ANA, 2014). Insere-se parcialmente na Bacia Hidrográfica do rio Ivinhema - BHRI (Arai, 2010), e integralmente na Bacia da Área Drenada pelo rio Paraná - BADRP, onde apresenta áreas com vulnerabilidade a inundação (Instituto de Meio Ambiente de Mato Grosso do Sul [IMASUL], 2015).

Figura 1: Localização da UHE Engenheiro Sérgio Motta (UHEESM) em relação as bacias hidrográficas do estado de Mato Grosso do Sul, no rio Paraná. BHRI = Bacia hidrográfica do rio Ivinhema; BHRP = Bacia Hidrográfica do rio Pardo; $\mathrm{BHRV}=$ Bacia Hidrográfica do Rio Verde. Em destaque os cinco trechos analisados.

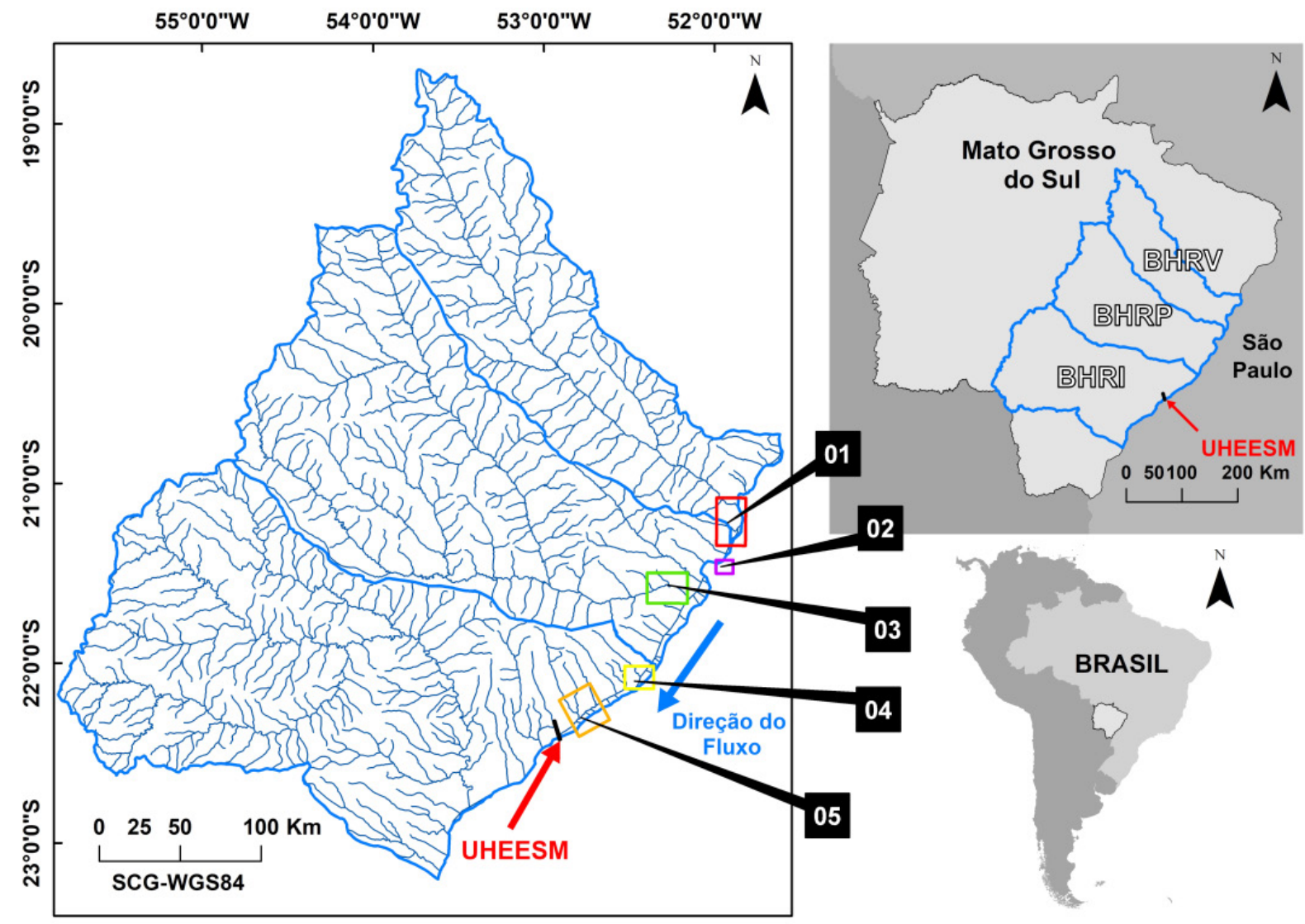

Fonte: elaborado a partir de dados da ANA (2020).

O acesso a UHEESM se dá pela Rodovia SP-613 no Km 78 (coordenadas UTM-22S 298739 E/ 7512326 N) ou com acesso fluvial 28 km a norte da confluência entre os rios Paraná e Paranapanema. A barragem conta com elevador, escada para peixes e uma eclusa que interliga o Brasil à rota do Mercado Comum do Sul (MERCOSUL). Situada na divisa dos Estados de São Paulo e Mato Grosso do Sul, este último teve grandes áreas submersa com a instalação da UHEESM, submergindo principalmente 35\% do território do munícipio de Anaurilândia (Oliveira, 2004).

Os solos da região são predominantemente Latossolos e Argissolos que ocupam o topo de colinas amplas, suaves e dissecadas, bem como morros baixos, escarpas serranas, planaltos e superfícies aplainadas degradadas (Serviço Geológico do Brasil [CPRM], 2009). Ocorrem Argissolos limítrofes à superfície de inundação e Planossolos próximos 
às margens dos principais cursos d'água afluentes da margem direita do rio Paraná. Associações complexas de Argissolos com Neossolos Quartzarênicos, Neossolos Litólicos e areias quartozosas inconsolidadas também são evidenciadas ao longo das margens do rio Paraná (Secretaria de Planejamento e Coordenação Geral [SEPLAN], 1988). O substrato rochoso genericamente é constituído por arenitos quartzosos, de granulação fina a média, secundariamente subarcoseanos e com boa maturidade textural, formando estratos tabulares, estratificações cruzadas e laminações plano-paralelas (CPRM, 2006a; CPRM, 2006b; CPRM, 2009).

O clima na região é tropical úmido continental, com média anual entre $20^{\circ} \mathrm{C}$ a $22^{\circ} \mathrm{C}$, e acentuada amplitude térmica anual, mensal e diária, inserida na trajetória de anticiclones polares, onde ocorrem episodicamente geadas durante outono e inverno (Oliveira, 2004). A média anual das chuvas varia de 1.300 a $1.500 \mathrm{~mm}$, sendo o verão o período com maior volume pluviométrico (cerca de $520 \mathrm{~mm}$ ), conforme média sazonal de uma série de 31 anos (Amador, 2017). Esta autora constata ainda registros de anos excepcionalmente chuvosos no verão e super secos na primavera, onde os maiores volumes de chuva mostram tendência de acúmulo ao final da estação de verão. As maiores precipitações ocorrem nas regiões de cabeceira, tal como as maiores vazões específicas médias de longa duração, sendo o rio Dourados o maior contribuinte potencial e real na BHRI (Arai, 2010). Com influência de anticiclone subtropical e zona de convergência do Atlântico Sul, e outros sistemas meteorológicos, esta região possui a menor taxa de precipitação acumulada durante a estação seca (junho, julho e agosto) em relação ao restante do Estado de Mato Grosso do Sul (Teodoro et al., 2016).

\section{MATERIAIS E MÉTODOS}

Foram selecionadas imagens dos satélites Landsat-5 TM (L5), Landsat-8 OLI (L8) e Sentinel-2 MSI (S2) disponíveis gratuitamente pelo no site oficial do Serviço Geológico Americano (USGS, 2020a), considerando um intervalo médio de 5 anos entre as imagens Landsat e o mesmo ano para as imagens Sentinel, conforme disponibilidade e limitações do intervalo de aquisição de cada série de imageamento (Tab. 1). Nas imagens L5 e L8 os valores digitais dos pixels foram convertidos a valores de radiância e em seguida reflectância no topo da atmosfera com auxílio do módulo i.atcorr integrado ao software QGis 3.10 . O detalhamento desse procedimento pode ser visto em Shiroma et al. (2020). Já a imagem do S2 adquirida no nível 1-C já possui a reflectância ortorretificada na atmosfera (TOA) e subpixel com registro multiespectral.

1 Disponível em: https://www.QGIS.org/pt_BR/site/forusers/download.html. 
Tabela 1: Filtragem e seleção de dados de imagens Landsat-5 TM, Landsat-8 OLI e Sentinel-2 MSI para o mesmo local em estudo.

\begin{tabular}{l|l|l|l|l|l|l}
\hline Data & Sensor & Órbita Ponto & $\begin{array}{l}\text { Cobertura de } \\
\text { Nuvens (\%) }\end{array}$ & Hora de Aquisição & $\begin{array}{l}\text { Ângulo Azimutal } \\
\text { Solar }\end{array}$ & $\begin{array}{l}\text { Ângulo Zenital } \\
\text { Solar }\end{array}$ \\
\hline $30 / 09 / 2019$ & L8 & $223 / 075$ & 0.0 & $13: 28: 46$ & 58,706905 & 57,217976 \\
\hline $28 / 09 / 2019$ & S2 & $124 /$ T22KCA & 9.5 & $13: 42: 09$ & 51,054578 & 30,038090 \\
\hline $08 / 09 / 2019$ & S2 & $124 /$ T22KCA & 16.3 & $15: 21: 24$ & 43,844004 & 36,887880 \\
\hline $08 / 09 / 2011$ & L5 & $223 / 075$ & 21.6 & $13: 17: 03$ & 53,022192 & 48,035318 \\
\hline $29 / 07 / 2008$ & L5 & $223 / 075$ & 1.3 & $13: 14: 53$ & 43,159120 & 37,047784 \\
\hline $18 / 09 / 2003$ & L5 & $223 / 075$ & 3.7 & $13: 06: 27$ & 59,307206 & 48,952825 \\
\hline $17 / 09 / 1997$ & L5 & $223 / 075$ & 0.0 & $13: 00: 54$ & 60,178959 & 47,795915 \\
\hline
\end{tabular}

Fonte: USGS (2020a).

De posse das imagens foi feito o empilhamento de bandas para composição simples de cor verdadeira e falsa-cor baseado em equação. A resolução espectral destes três sensores multiespectrais é similar (Fig. 2), abrangendo faixas do espectro eletromagnético compatíveis para comparação em estudos ambientais, pois mostram correlação quase perfeita para cenas do mesmo dia e área, podendo ser usadas conjuntamente para criar séries temporais de observação mais densas para avaliar mudanças na paisagem (Runge \& Grosse, 2019).

Figura 2: Comparação entre faixas de espectro de imagens Landsat-5 TM, Landsat-8 OLI e Sentinel-2 MSI.

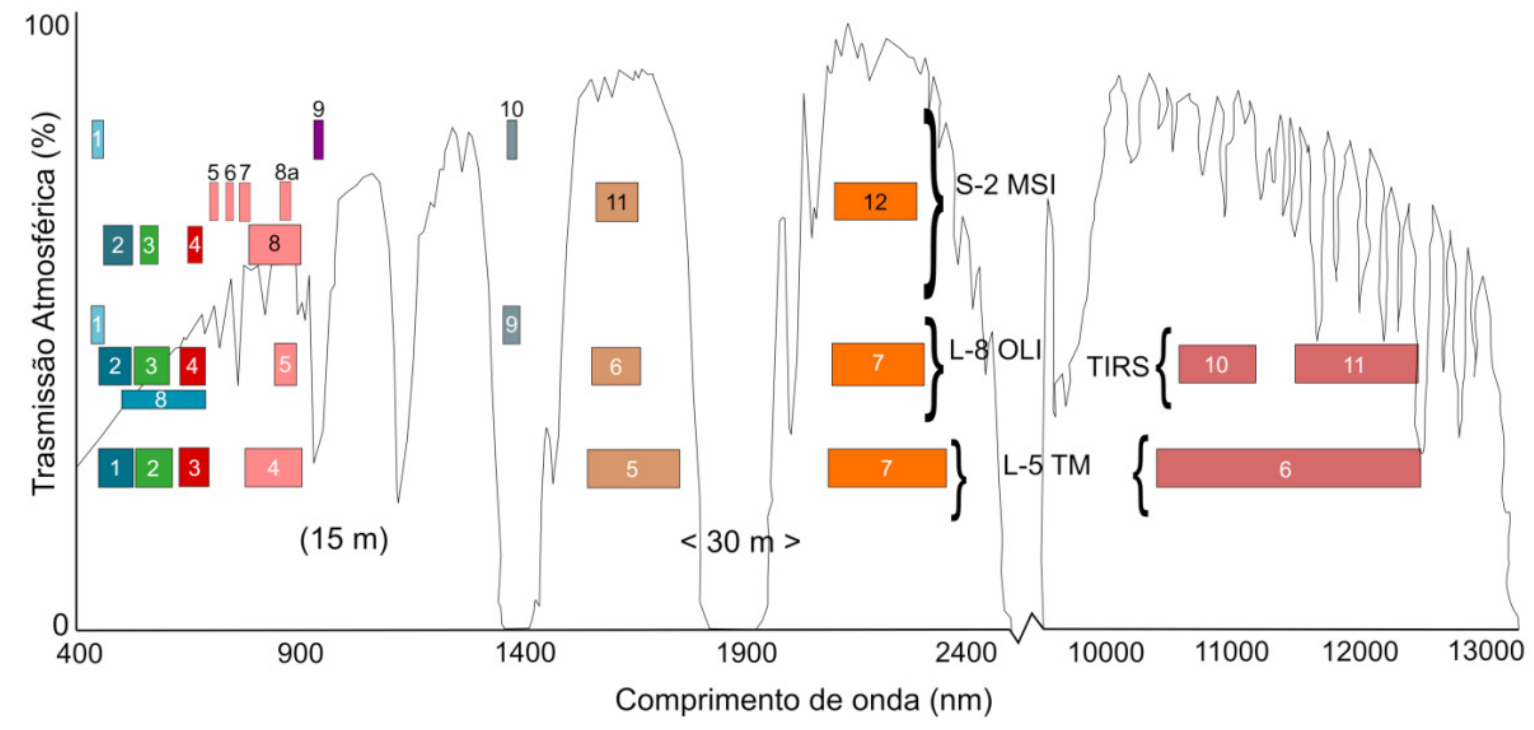

Fonte: editado de USGS (2020b).

Wang et al. (2018), visando o mapeamento preciso de corpos hídricos, propuseram o Índice Multiespectral de Água Completo e Revisado (MuWi-C e MuWI-R), com a utilização de bandas multiespectrais do S2 (Equação 1), suprimiram as limitações do Índice de Água por Diferença Normalizada - NDWI - (Mc Feeters, 1996), do Índice Modificado de Água por Diferença Normalizada $(X u, 2006)$ e do Índice Automático de Extração de Água (Feyisa, Meilby, Fensholt \& Orgulhoso, 2014). O MuWi-C obtém maior precisão geral, porém o $\mathrm{MuWi}$-R, tendo em vista sua maior simplicidade de cálculo, também executa com ótimo 
desempenho e acurácia, sendo que ambos os índices reduziram as classificações errôneas de sombra e brilho solar sobre corpos hídricos, em relação aos propostos anteriormente.

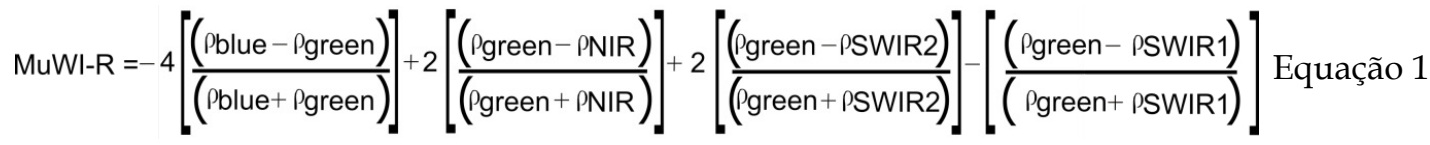

Onde:

$\rho_{\text {blue: }}$ É a reflectância na banda do azul (coc: $\left.0,490 \mu \mathrm{m}\right)$;

$\rho_{\text {green: }}$ É a reflectância na banda do verde (coc: $\left.0,560 \mu \mathrm{m}\right)$;

$\rho_{\mathrm{NIR}}$ : É a reflectância na banda do infravermelho próximo (coc: $0.842 \mu \mathrm{m}$ );

$\rho_{\text {SWIR1: }}$ É a reflectância na banda do infravermelho de ondas curtas (coc: $1.610 \mu \mathrm{m}$ );

$\rho_{\text {SWIR2: }}$ É a reflectância na banda do infravermelho de ondas curtas (coc: $2.190 \mu \mathrm{m}$ ); $\operatorname{coc}=$ comprimento de onda no centro.

Para o realce de características da água por imagem de satélite utilizamos o repositório GitHub, o qual funciona como plataforma colaborativa de hospedagem de código-fonte livre e aberto para programadores e usuários em geral. Acessamos o repositório sobre composições de imagens Sentinel disponibilizada por Volkmer (2020). Este autor originalmente utilizou nas composições VNIR-VRE1, VNIR-VRE2, VRE-VIS, e o NDWI de McFeeters (1996) mas neste estudo substituímos o NDWI pelo MuWi-R de Wang et al. (2018), conforme o Quadro 1.

Quadro 1: Utilização da mesma configuração para visualização e realce das imagens pós-composição simples e baseada em equação entre bandas multiespectrais.

\begin{tabular}{|c|}
\hline Landsat-5 TM, Landsat-8 OLI e Sentinel-2 MSI \\
\hline Contraste: 23 \\
\hline Brilho: 15 \\
\hline Transparência: 0 \\
\hline Fundo: ativo \\
\hline Ajuste de faixa dinâmico: ativo \\
\hline TopUp: ativo \\
\hline Histograma: Porcentagem de corte \\
\hline
\end{tabular}

Fonte: editado em Image Analysis do ArcMap (Environmental Systems Research Institute. [ESRI], 2013).

Para permitir melhor comparação entre os objetos hídricos e não hídricos, foram equalizados os parâmetros de ajuste fino da imagem, conforme o conjunto de Equações 2. 
Equações 2: Equações aplicadas para composição RGB das bandas multiespectrais. O NDWI de McFeeters (1996), na composição proposta por Volkmer (2020), foi susbtituído pelo MuWI-R de Wang et al. (2018).

VNIR-VRE1

$$
\begin{gathered}
R=\left[\left(\rho_{\text {red }} * 7\right)-(\rho \text { NIR } * 7)\right] * \text { MuWI-R } \\
G=\left(\rho_{\text {red edge } 2} * 7\right) \\
B=\left(\rho_{\text {blue }} * 3\right)
\end{gathered}
$$

Sentinel 2 - MSI

VNIR-VRE2

$$
\begin{gathered}
R=\left[\left(\rho_{\text {red }} * 7.5\right)-(\rho \mathrm{NIR} * 4)\right] \\
G=\left[\left(\rho_{\text {green }} * 2\right)+\left(\rho_{\text {red edge }}{ }^{* 6}\right)\right] \\
B=\left[\left(\rho_{\text {blue }} * 4\right)+\text { MuWI-R }\right]
\end{gathered}
$$

VRE-VIS

$$
\begin{gathered}
R=\left[\left(\rho_{\text {red }} * 3\right)-\rho_{\text {red edge } 1}\right] \\
G=\left[\left(\rho_{\text {green }} * 3\right)+\rho \text { NIR }\right] \\
B=\left(\rho_{\text {blue }} * 3.5\right)
\end{gathered}
$$

Onde:

$\rho_{\text {red: }}$ É a reflectância na banda do vermelho (coc: 0,665 $\left.\mu \mathrm{m}\right)$;

$\rho_{\text {red edge1: }}$ É a reflectância na banda de borda do vermelho (coc: 0,705 $\left.\mu \mathrm{m}\right)$;

$\rho_{\text {red edge2: }}$ É a reflectância na banda de borda do vermelho (coc: 0,740 $\left.\mu \mathrm{m}\right)$;

Em seguida coletamos amostras de pixels representativos que indicam, através da diferença da cor da água, mudanças qualitativas em relação à turbidez, vazão e profundidade relativa ao nível de base local, gerando assim uma chave de classificação individualizada a partir dos níveis de cor RGB de cada pixel, extraídas com o software gratuito Just Color Picker ${ }^{2}$. De posse desse resultado foi feita a comparação entre as séries temporais das imagens L5 e L8 considerando os anos de 2003, 2008, 2011 e 2019. Já para as imagens S2 comparamos a interferência de cenas com baixa e média nebulosidade para diagnóstico dos mesmos parâmetros na água, para duas datas do mês de setembro de 2019 .

Imagens do lapso de tempo, históricas e gratuitamente acessíveis do Google Earth $P_{r o}{ }^{3}$ foram utilizadas para dar suporte à delimitação das faixas de áreas de preservação permanente (APP) pré e pós-inundação, áreas de pastoreio do gado, cicatrizes de movimentos de massa nas margens e nos afluentes do rio Paraná. Em campo com aeronave remotamente pilotada (RPA) coletamos imagens que mostram em detalhe o transporte de sedimentos nos taludes da margem direita do canal principal e os principais danos advindos desse processo atualmente ativo.

Empregamos a imagem de radar ALOS Palsar modo FDB de resolução nativa de 12,5 metros (Alaska Satellite Facility, 2010), extraindo os pontos cotados do modelo digital de elevação e interpolando estes valores pelo método topo to raster, os quais foram reamostrados para resolução espacial de 10 metros no ArcGIS versão 10.2.1. A partir deste produto obtivemos intervalos de altimetria e declividade do terreno. Os mapas de pedológico (SEPLAN, 1988) e litológico (CPRM, 2006a; CPRM, 2006b; CPRM, 2009), todos em escala 1:1. 000.000, foram agregados aos dados de movimentos de massa e de nascentes obtidos em campo, permitindo a geração de um perfil topográfico esquemático, representando

2 Disponível em: https://annystudio.com/software/colorpicker/

3 Google Earth Pro: version 7.3.2.5776. 2019. Disponível em: https://www.google.com.br/earth/download/gep/agree.html 
sinteticamente os processos atuantes no meio físico da zona de perturbação mais próxima ao barramento (área 05). A Figura 3 apresenta uma síntese do método empregado neste estudo.

Figura 3: Fluxograma dos materiais e métodos. L5 = Landsat-5 TM, L8 = Landsat-8 OLI, S2 = Sentinel-2 MSI, GE = Google Earth, RPA = Aeronave Remotamente Pilotada, AP = Alos Palsar.

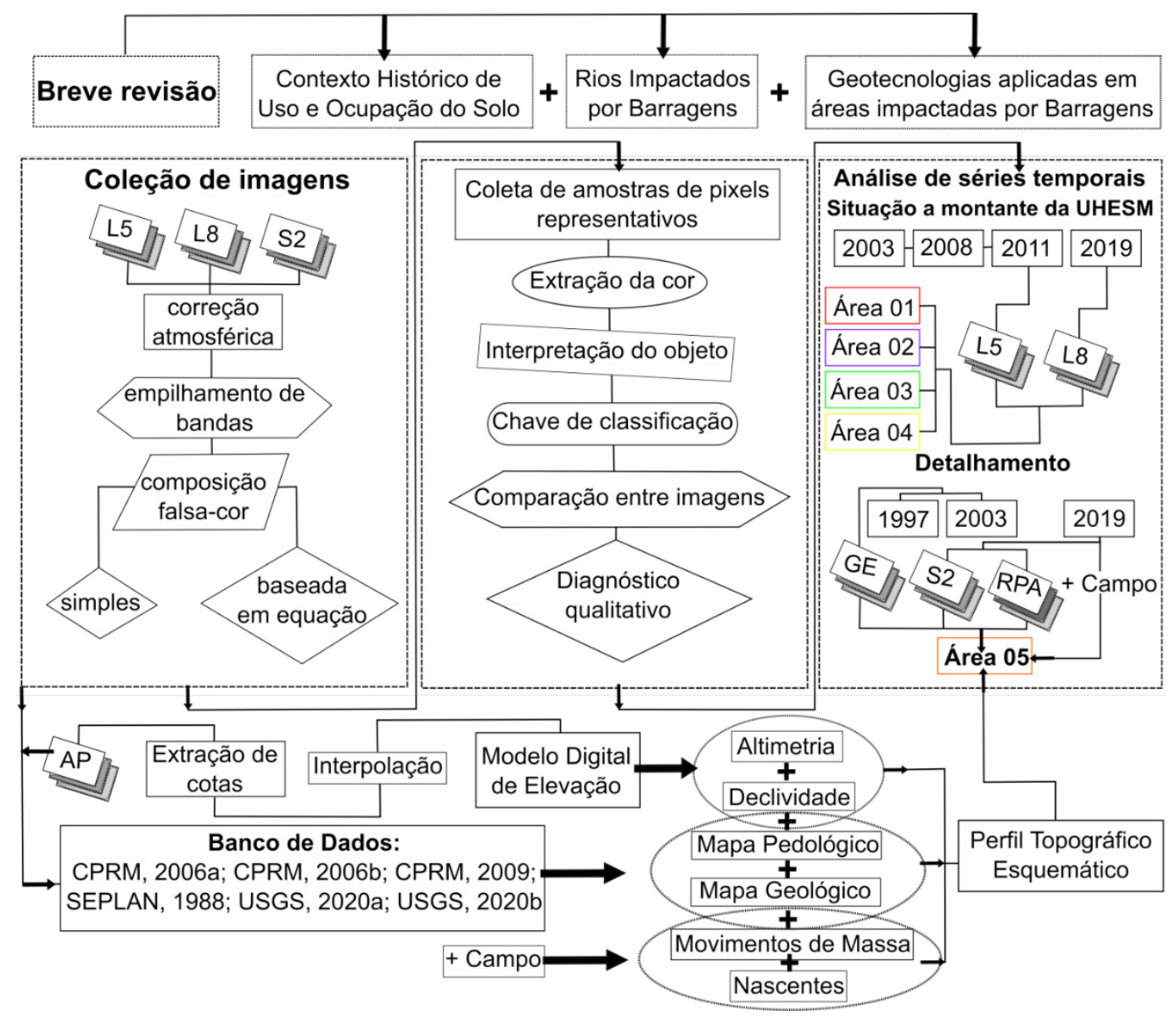

\section{RESULTADOS E DISCUSSÃO}

\section{Contexto histórico e legislação específica}

O início da construção da UHEESM, em 1979, e o seu projeto básico (1978) foram realizados sem a exigência de Estudo de Impacto Ambiental (EIA), pois não havia leis nem regulamentações sobre o tema à época (Oliveira, 2004). Porém em 1980, a Companhia Energética de São Paulo editou o Controle Ambiental e Aproveitamento Múltiplo do Reservatório Porto Primavera, prevendo e definindo Área de Influência, Área de Desapropriação e Área de Inundação (Oliveira, 2004). Durante esse processo várias famílias foram indenizadas e reassentadas, com resgates da fauna silvestre. O preenchimento da UHEESM, apesar de trazer medidas compensatórias e mitigatórias, não previu ações suficientes para controlar danos provenientes da erosão marginal do rio Paraná e seus tributários, conforme previsto no Programa de Controle Ambiental (Oliveira, 2004). 
As fronteiras, a demarcação e ocupação das terras nesta região se intensificaram com a campanha Marcha para Oeste (1937-1945), porém já havia migrações desde o início da década de 1930, com derrubada de florestas, forja da civilidade intervencionista e expansionista, promovida pela migração de sulistas, nordestinos e paulistas (Rosa, Ferreira \& Rosa, 2018). A porção sul e leste do Mato Grosso do Sul teve assentamentos instalados durante o período de 2001 a 2002, porém muito aquém do planejado, sem aplicação significativa da reforma agrária no Estado (Fachin, 2016). Nas últimas décadas, a expansão canavieira substituiu antigas áreas de lavouras e pecuárias, sobretudo na BHRI, sendo ausentes políticas que regulamentem o uso do solo agrícola (Teixeira \& Hespanhol, 2012).

A qualidade da água nesta região pode estar sendo impactada pela intensa adubação artificial, uma vez que os solos desenvolvidos sobre os arenitos são desprovidos de elementos químicos vitais ao desenvolvimento agrícola. Nesse sentido as perdas de solo anual, também promovem lixiviação da adubação empregada no cultivo da cana-de-açucar (Araújo, Furrier \& Monteiro, 2016).

Nas drenagens artificiais de veredas, vêm ocorrendo eventos sazonais de queimadas, o que tem provocado o rebaixamento do nível freático ao longo da BHRI, afetando os buritizais, os quais são considerados APPs, por estarem associados ao limite da faixa de inundação (Pott, Silva \& Gomes, 2014). Outra demanda é o fortalecimento de políticas públicas aplicadas de forma descentralizada e compartilhada para atender expectativas dos comitês de bacias hidrográficas (CBHs) locais e regionais (Bataghin et al., 2017). Atualmente o CBH-Ivinhema passa por aperfeiçoamento técnico e cultural por parte de seus membros e busca com apoio do IMASUL para captar recursos financeiros para desenvolver Programas de Gestão Ambiental (Pepe \& Berezuk, 2013). A lei Estadual $n^{\circ}$ 2.406, de 29 de janeiro de 2002, institui a Política Estadual de Recursos Hídricos e cria o Sistema Estadual de Gerenciamento de Recursos Hídricos, onde em seu Artigo $3^{\circ}$ parágrafo $1^{\circ}$ diz que compete ao IMASUL outorgar e fiscalizar o direito de uso dos recursos hídricos. Sendo assim, o regime de outorga visa assegurar o controle quantitativo e qualitativo do uso das águas superficiais e subterrâneas, bem como o efetivo exercício dos direitos de acesso à água (Fernandes \& Oliveira, 2018).

\section{Rios impactados por barragens}

Erosão, transporte e deposição nos ambientes fluviais variam ao longo do tempo e são interdependentes, causando mudança no fluxo e na carga existente (Coelho, 2008). A velocidade da água depende principalmente de fatores geomorfológicos e hidrológicos, tais como os padrões de drenagem e da geometria do leito geram variações nos diversos setores do canal no qual a água flui, e culminam em processos específicos de erosão, transporte e deposição (Coelho, 2008). O Quadro 2 distingue entre os três principais setores da bacia hidrográfica os impactos hidrológicos e geomorfológicos promovidos por barramentos de canais fluviais. 
Quadro 2: Alterações hidrológicas e geomorfológicas em setores de rio represado.

\begin{tabular}{|c|c|c|}
\hline $\begin{array}{l}\text { SETOR } \\
\text { DA BACIA }\end{array}$ & PRINCIPAIS IMPACTOS HIDROLÓGICOS & $\begin{array}{l}\text { PRINCIPAIS IMPACTOS } \\
\text { GEOMORFOLÓGICOS }\end{array}$ \\
\hline $\begin{array}{l}\text { Montante da } \\
\text { barragem }\end{array}$ & $\begin{array}{l}\text { Deposição de carga sólida; } \\
\text { Mudança térmica das águas; } \\
\text { Redução da velocidade do fluxo; } \\
\text { Ascenção do nível de base local; } \\
\text { Criação de lago; } \\
\text { Modificação do balanço hidríco; } \\
\text { Alteração na qualidade da água; } \\
\text { Estratificação térmica da água; } \\
\text { Diminuição da vazão média por aumento da } \\
\text { evaporação*. }\end{array}$ & $\begin{array}{l}\text { Assoreamento na desembocadura dos rios } \\
\text { principais; } \\
\text { Assoreamento no fundo dos vales principais; } \\
\text { Assoreamento na desembocadura e no fundo } \\
\text { dos vales afluentes; } \\
\text { Formação de novas áreas de inundação. }\end{array}$ \\
\hline $\begin{array}{l}\text { No reservatório } \\
\text { e periferia }\end{array}$ & $\begin{array}{l}\text { Armazenamento de carga líquida; } \\
\text { Armazenamento de carga sólida; } \\
\text { Modificação no conteúdo de gases dissolvidos; } \\
\text { Elevação do nível piezométrico } \\
\text { (compressibilidade dos líquidos); } \\
\text { Alteração nas taxas de infiltração; } \\
\text { Maior disponibilidade de água subterrânea; } \\
\text { Ocorrência de inundações; } \\
\text { Assoreamento no reservatório; } \\
\text { Redução da vida útil da barragem; } \\
\text { Alteração na transparência da água; } \\
\text { Alteração na estrutura térmica da água. }\end{array}$ & $\begin{array}{l}\text { Submersão das formas de relevo; } \\
\text { Processos de abrasão lacustre; } \\
\text { Recuo das margens ou das falésias lacustres; } \\
\text { Formação de praias e depósitos de abrasão; } \\
\text { Processos de assoreamento; } \\
\text { Formação de bancos arenosos emersos ou } \\
\text { imersos; } \\
\text { Formação de lagoas fechadas; } \\
\text { Colmatação da desembocadura dos rios } \\
\text { principais; } \\
\text { Formação de novas áreas de inundação. }\end{array}$ \\
\hline $\begin{array}{l}\text { A jusante da } \\
\text { barragem }\end{array}$ & $\begin{array}{l}\text { Controle da regularização das descargas; } \\
\text { Redução da carga sólida transportada e da } \\
\text { turbidez da água; } \\
\text { Modificação das características de transporte da } \\
\text { carga de fundo; } \\
\text { Salinização da água; } \\
\text { Alteração na estrutura térmica; } \\
\text { Redução do nível piezométrico; } \\
\text { Alterações nas taxas de infiltração; } \\
\text { Menor disponibilidade de água subterrânea; } \\
\text { Redução na variabilidade sazonal e na } \\
\text { magnitude das cheias; } \\
\text { Alteração no padrão de variação de temperatura } \\
\text { da água*. }\end{array}$ & $\begin{array}{l}\text { Entalhe no leito do rio, com consequente } \\
\text { descida do nível de base local; } \\
\text { Modificação nas taxas de erosão de ilhas e } \\
\text { margens; } \\
\text { Descida do nível de base dos afluentes com } \\
\text { retomada erosiva (entalhe) dos seus leitos; } \\
\text { Processos de erosão nas margens; } \\
\text { Alteração nos sedimentos de fundo e das } \\
\text { margens; } \\
\text { Reajustamento na morfologia do canal pela } \\
\text { migração dos setores de erosão e sedimentação; } \\
\text { Processos de deposição nas margens e fundo do } \\
\text { leito e alteração na textura da carga de fundo; } \\
\text { Alteração na pendente; } \\
\text { Modificações na dinâmica da foz. }\end{array}$ \\
\hline
\end{tabular}

*Efeitos mais evidentes em rios de clima temperado ou semiárido.

Fonte: Cunha (1995) apud Coelho (2008), Petts (1984, 1999), Downs e Gregory (2004), Stevaux et al. (2009), Martins (2008) e Stevaux, Martins e Meurer (2009) apud Stevaux e Latrubesse (2017).

Os principais impactos ambientais presentes na área drenada pelo rio Paraná (BADRP) são assoreamento, aumento de queimadas e redução do pescado. Dentre as formas de uso e ocupação do solo predominam a agricultura (39\%) e pastagens (22\%), com aptidão agrícola para este tipo de atividade (IMASUL, 2015). Este mesmo órgão aponta que quase metade $(47 \%)$ das nascentes não possui a faixa mínima de APP preservada, sendo cerca de $38 \%$ apropriadas por atividades agropecuárias. O maior uso de recursos hídricos está ligado à irrigação e dessedentação de animais, onde o panorama de impactos ambientais já produziu efeitos de diminuição da produtividade econômica e degradação da fauna e da flora aquática (IMASUL, 2015). Fatores como desrespeito ou desconhecimento da legislação vigente e aspectos econômicos e culturais aliados, ou não, à omissão do poder público nas mais diversas esferas podem conduzir a este panorama (Santos et al., 2016). 


\section{Uso de geotecnologias em áreas impactadas por barragens}

Imagens de satélite e cartas temáticas de detalhe são imprescindíveis para caracterização e análise de obras de engenharia que causam grandes mudanças na geomorfologia fluvial, como é o caso de rios impactados por barragens, pois fornecem dados qualitativos e quantitativos essenciais (Araújo, Furrier \& Monteiro, 2016). Escaneamento terrestre móvel aliado a tecnologias de deteç̧ão de altimetria variável com geração de nuvem de pontos (Laser Scanner e LiDAR) são também alternativas ao monitoramento da dinâmica erosiva marginal em reservatórios, podendo ser implementado integração de imagens RGB para classificações e filtros automatizados (Tommaselli, Moraes, Silva, Rubio, Carvalho \& Tommaselli, 2014). Para fornecer diagnósticos das mudanças na morfologia fluvial de rios impactados por barragens, Coelho e Cunha (2019) propõem o monitoramento por análises multitemporais com planos de informações em várias escalas cartográficas em sistemas de informações geográficas, campanhas de campo com entrevistas a comunidade local e estimador kernel para identificar onde as erosões marginais são mais intensas. Com sensoriamento remoto é possível diagnosticar quali-quantitativamente as variáveis físico-químicas da água, maximizando o potencial do monitoramento indireto e embasando a tomada de decisões protetivas e preventivas, sendo que em rios geralmente são avaliados parâmetros tais como transporte de sedimentos, erodibilidade, qualidade da água, carreamento e fixação de nutrientes, entre outros (Lima, Motta, Souza, Guirra, \& Paranhos Filho, 2019).

\section{Diagnóstico dos impactos ambientais na zona de pertubação de reservatório tropical}

A banda individual de cada satélite pode ser aplicada para discriminar objetos terrestres e aquáticos em níveis de cinza, porém quando empilhadas podem gerar uma combinação cor-verdadeira ou falsa-cor com amplo espectro cromático no sistema vermelho-verde-azul (RGB). Sendo assim, a banda do azul das imagens L5, L8 e S2 são úteis para mapear o nível batimétrico e delimitar corpos hídricos, diferenciando-os do solo, da vegetação e de áreas construídas. Enquanto a banda do verde destes satélites enfatiza sedimentos em suspensão, a banda do vermelho permite maior contrate de áreas com e sem vegetação (Franco, 2017). Nesse contexto, obtivemos da composição entre estas bandas a chave de classificação apresentadas na Figura 4. 
Figura 4: Legenda para classificação de corpo hídrico em relação à turbidez, profundidade relativa do nível d'água e vazão em resposta a refletância dos objetos na composição colorida das imagens de satélite.

Legenda de classificação de corpos hídricos proposta neste estudo, baseada na composição
RGB dos sensores: Landsat-5 TM (321), Landsat-8 OLI (432) e Sentinel-2 MSI (432)

Faixa de cores detalhada para objetos hídricos:

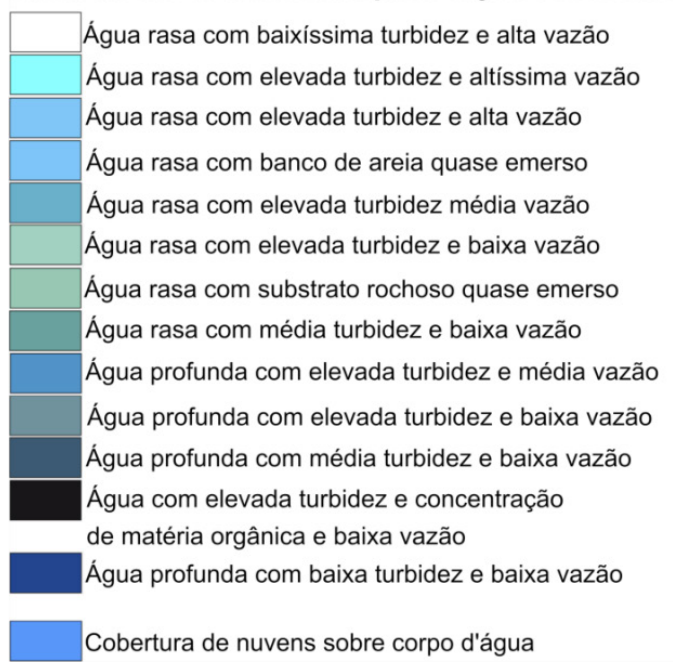

Faixa de cores genérica proposta para objetos não-hídricos:

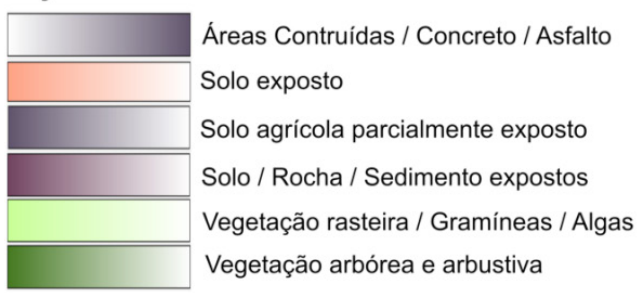

Ao analisarmos a Área 01 (Fig. 5) identificamos a planície aluvial na confluência entre o rio Verde com o rio Paraná, contendo pântanos e lagoas concatenadas que compõe a planície de inundação, com corte de colo de meandro. A turbidez da água ao longo de toda série temporal é maior na margem direita, onde uma ilha fluvial alongada no centro do canal principal de drenagem isola a carga sedimentar oriunda dos tributários da parte sul-matogrossense. Nesta série verifica-se que o período com maior turbidez na margem direita do rio Paraná ocorre na na cena (A) de 2003; já em 2008 (B) fica nítido o acúmulo de sedimentos na confluência de afluente da margem direita do rio Paraná, devido a mudança do vetor de transprote do fluxo, diminuindo a energia do transporte. Em (C), uma cena de 2011, ocorre a interferência da cobertura de nuvens, a qual mascara a batimetria e o material particulado na água. Na cena de 2019 (D) tem-se a dispersão de sedimentos finos em ambas as margens devido a maior turbulência das correntes, provavelmente influênciada por ventos. 
Figura 5: Avaliação da área 01 em quatro cenas A, B, C e D.
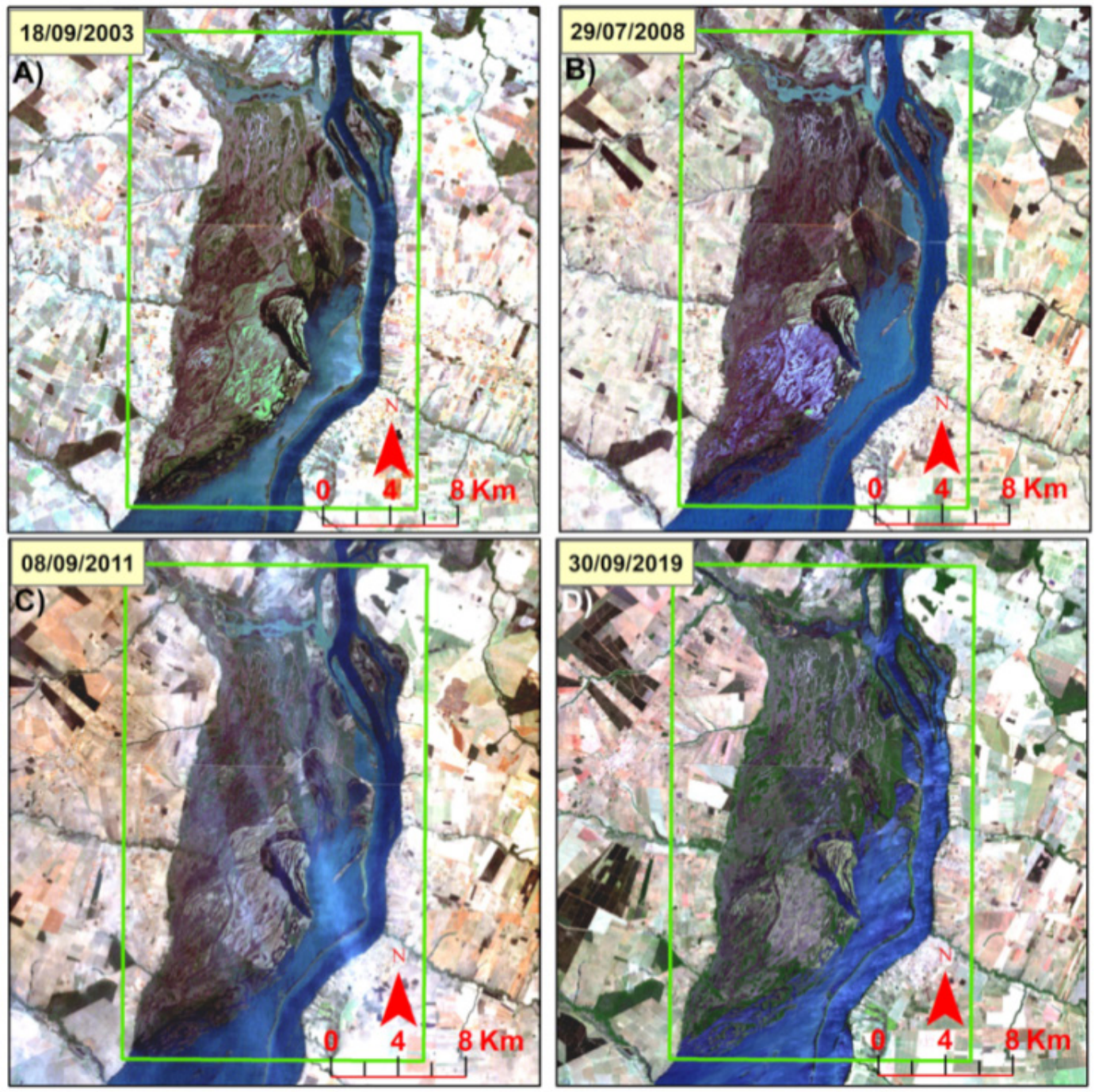

A área 02 mostra a confluência do rio do Peixe (margem paulista) com o rio Paraná (Fig. 6), onde observa-se a influência do regime de vazão provocado pela abertura das comportas, a qual interfere diretamente na turbidez da água. Em cena de 2003 (A) ocorreu o período de menor vazão e maior redução do nível d'água, expondo rochas no leito e na base da barragem, com elevada turbidez destacada em tons de azul esverdeados mais claros. A cena de 2008 (B) mostra a subida do nível d'água em relação a cena anterior, que submerge grande parte das rochas do leito. Verifica-se que este evento possibilita maior dissolução de sedimentos finos e decantação, o que diminui a turbidez. Em (C), cena de 2011, se apresenta um período com nível d'água ainda mais elevado do que o anterior, onde a turbidez oriunda de sedimentos transportados e em suspensão pelo rio do Peixe é realçada. Em 2019 (D), com abertura das comportas, houve aumento expressivo da vazão onde a mistura água/sedimento aumenta a refletância do corpo hídrico, devido a presença de vapor d'água e sedimentos areno-argilosos em movimento caótico de saltação. 
Figura 6: Avaliação da área 02 em quatro cenas A, B, C e D.
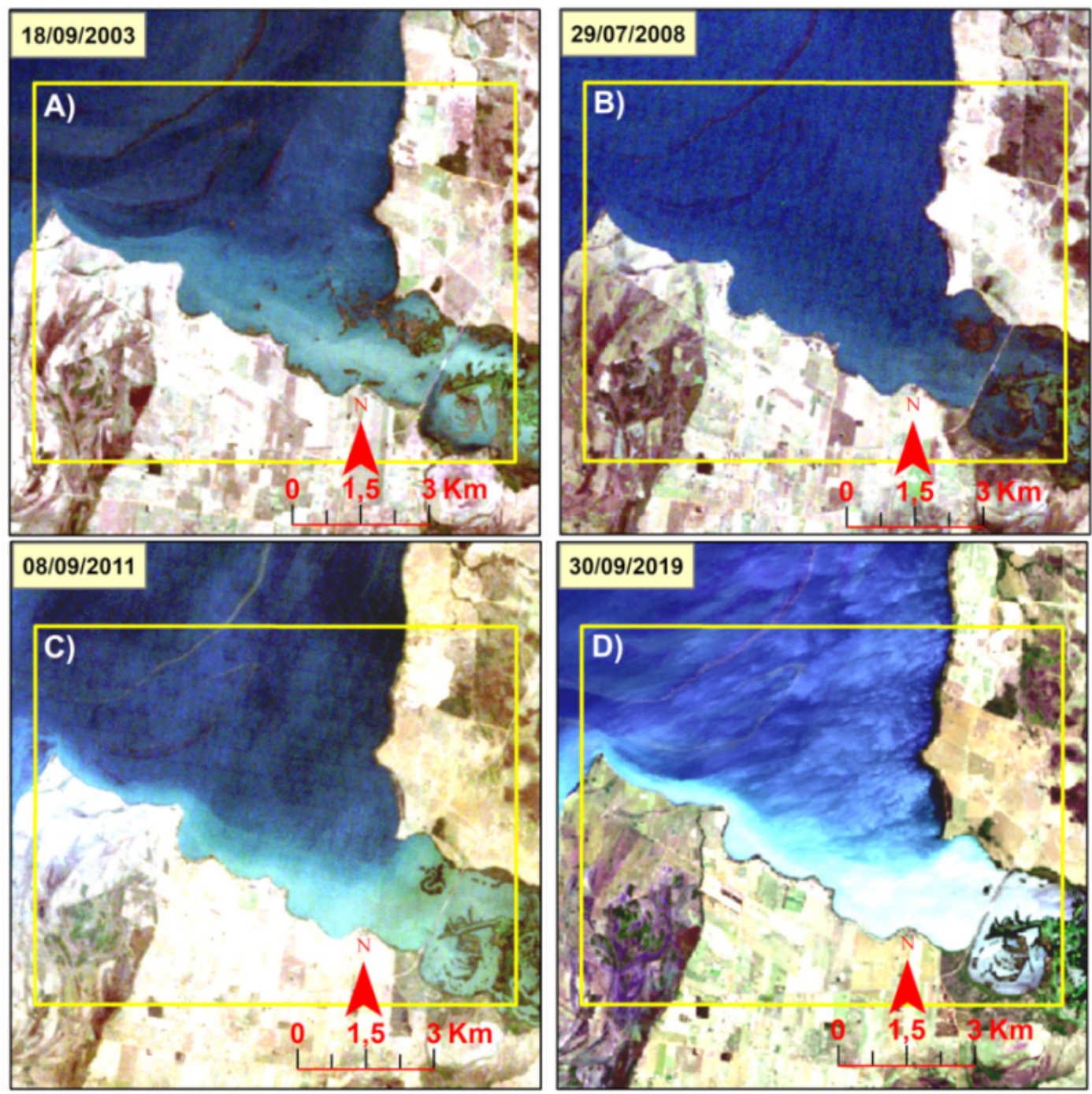

Na área 03 (Fig. 7) observa-se para a cena de 2003 (A), 2008 (B), 2011 (C) e 2019 (D) a manutenção contínua de elevada capacidade de transporte de sedimentos da bacia de drenagem do rio Pardo, contribuindo com elevado aporte de material em suspensão para dentro do rio Paraná, e consequentemente elevada turbidez. Provavelmente há um incremento da velocidade de escoamento e da energia do fluxo turbulento em (D), tendo em vista que a frente de deposição da pluma de sedimentos alcança maior distância quando comparada aos períodos anteriores. 
Figura 7: Avaliação da área 03 em quatro cenas A, B, C e D.
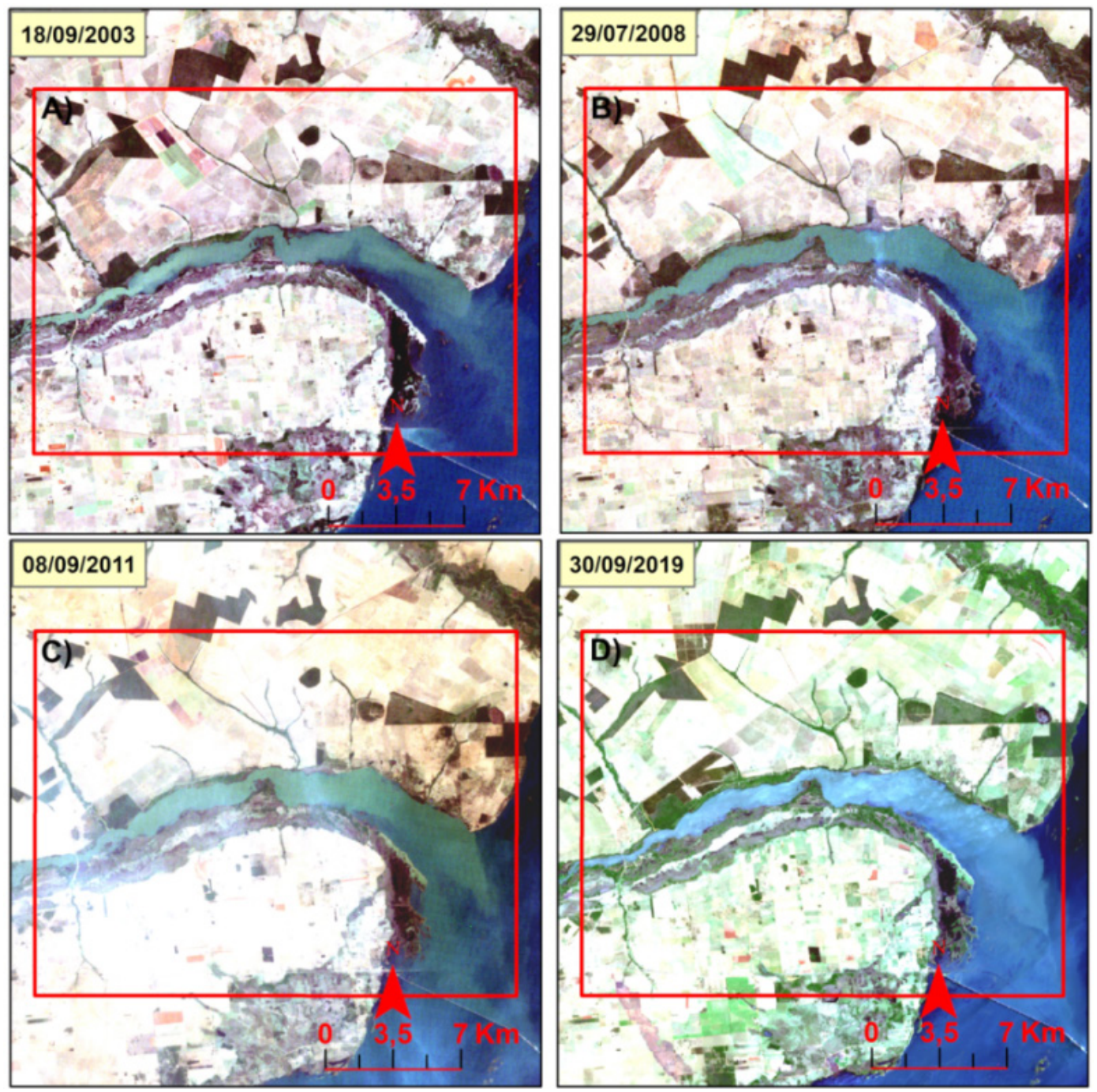

Na Área 04 (Fig. 8) tem-se ilhas fluviais e ressaco, onde há uma zona de baixa velocidade de fluxo, favorecendo a decantação de material fino da corrente e a separação do fluxo. Em (A) ocorre a emersão do leito rochoso na margem direita, em (B) a mudança da tonalidade da água indica maior turbidez em relação à (A). Em (C) mostra a influência das nuvens sobre a visibilidiade dos objetos no corpo hídrico, e em (D) é realçado o transporte de sedimentos ao longo das margens devido a erosão das mesmas, além da descarga de sedimentos dos tributários do rio Paraná (ribeirão Quiteroizinho na margem direita e ribeirão das Pedras na margem esquerda), com vegetação cobrindo as ilhas fluviais estabilizadas. 
Figura 8: Avaliação da área 04 em quatro cenas A, B, C e D
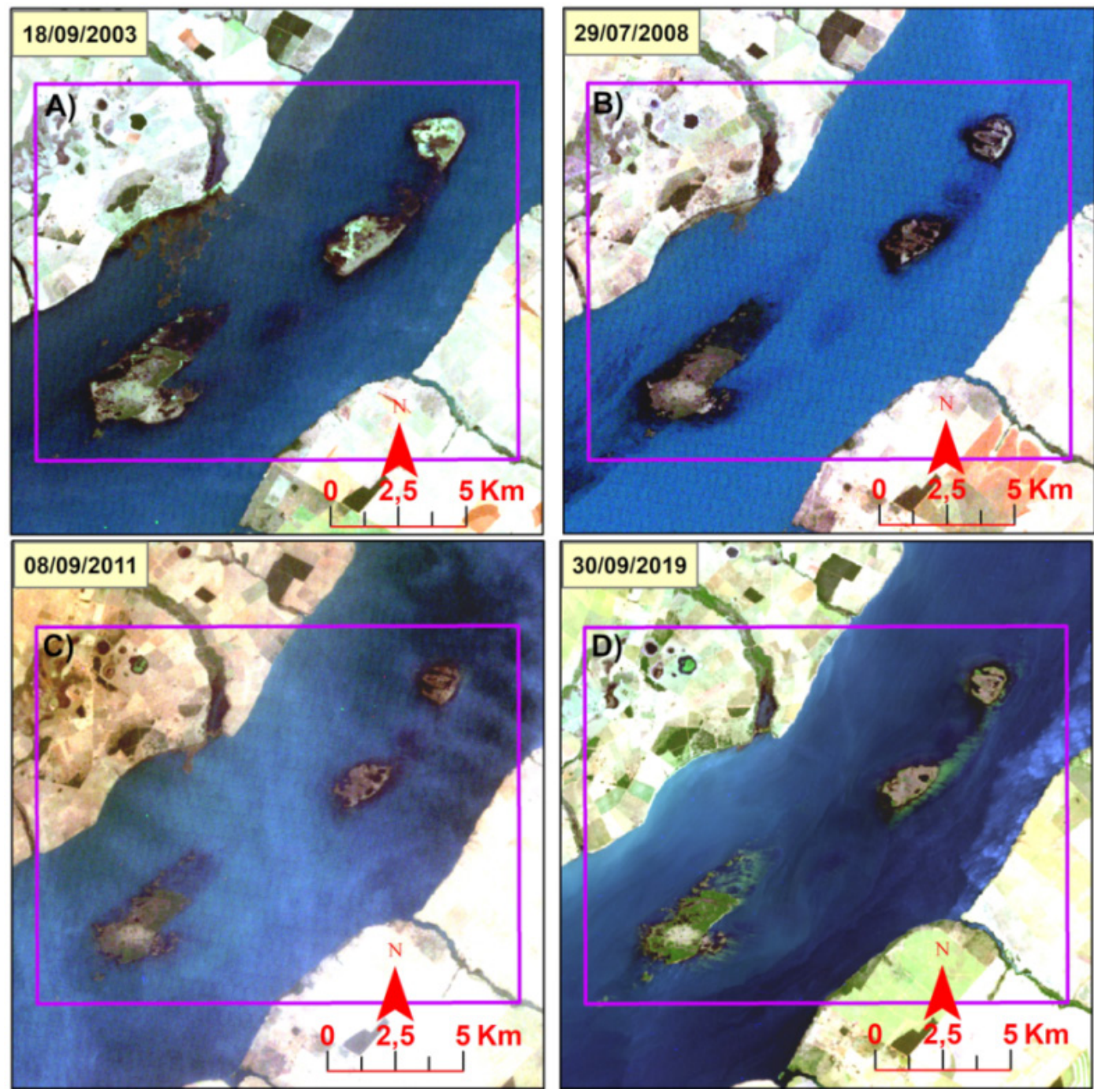

A área 05 (Fig. 9) mostra a comparação entre composições coloridas cores-verdadeira das imagens L8 eS2 (com nuvem e sem nuvem) no mês de setembro de 2019. Em (A) tem-se o contraste entre água pouco turva (azul escuro) com água muito turva (azul claro) - esta última se concentra na margem direita do rio Paraná e apresenta na superfície da água uma textura lisa. Em (B) ocorre a interferência das nuvens na cor, contraste e nitidez da imagem e em (C) a superfície da água apresenta padrão rugoso, onde a cor, o contraste e a nitidez são realçados, devido a melhor resolução espacial e a baixa densidade de nuvens, sendo perceptível a tendência do aumento da turdidez (azul mais claro) na margem direita do rio Paraná. 
Figura 9: Avaliação da área 05 em três cenas A, B e C com cores verdadeiras em imagens L8 e S2.
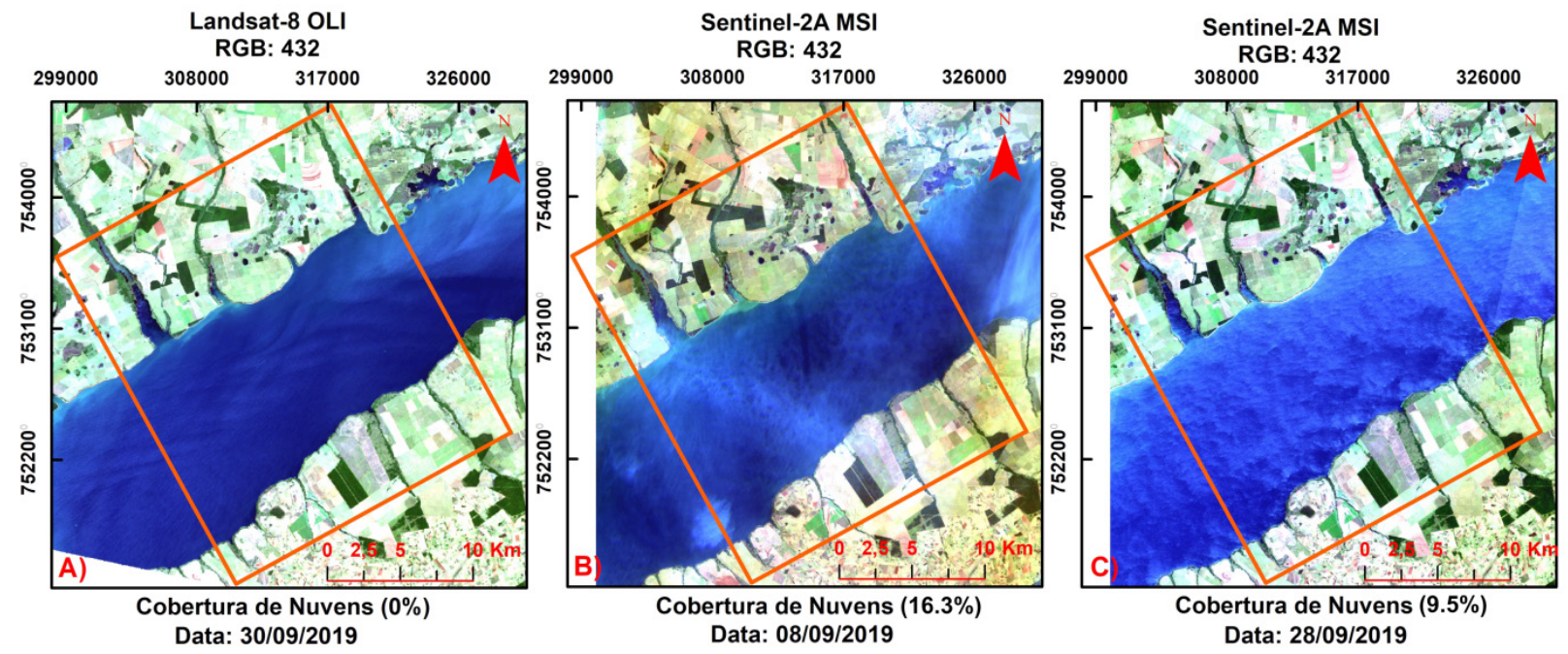

Com a aplicação da composição de bandas, baseada em equação (Fig. 10), obtem-se a comparação entre imagens S2 com alta nebulosidade e com baixa nebulosidade. Verificase que a acurácia visual de objetos na água na composição VNIR-VRE1 (A) e (B) realça a profundidade da lâmina d'água e a rugosidade do canal, porém é fortemente influênciada por nuvens, mesmo que esta esteja em porcentagens menores do que $20 \%$ de cobertura na área, modificando significativamente a reflectância dos objetos e a reamostragem dos pixels. A Composição VNIR-VRE2 (A) e (B) realça melhor a profundidade da lâmina d'água no canal principal em relação a VNIR-VRE1 e a VRE-VIS, reduzindo a rugosidade da imagem, porém é fortemente prejudicada pela presença de nuvens, até mais do que VNIR-VRE1. A VRE-VIS (A) e (B) consegue realçar o solo exposto e diminuir a interferência das nuvens na imagem. Em comum a todas as composições de bandas, ao utilizarem bandas espectrais na borda do vermelho (red edge), infravermelho próximo e azul, permitiram a detecção de turbidez em águas opticamente rasas. O S2 capta bem a batimetria em até 10 metros de profundidade, apresentando erros de até 0,58 metros em profundidades que variam de 0 a 18 metros (Caballero, Stumpf \& Meredith, 2019). 
Figura 10: Comparação entre imagens Sentinel-2 MSI com presença e com ausência de nuvens na acurácia visual de objetos na água.
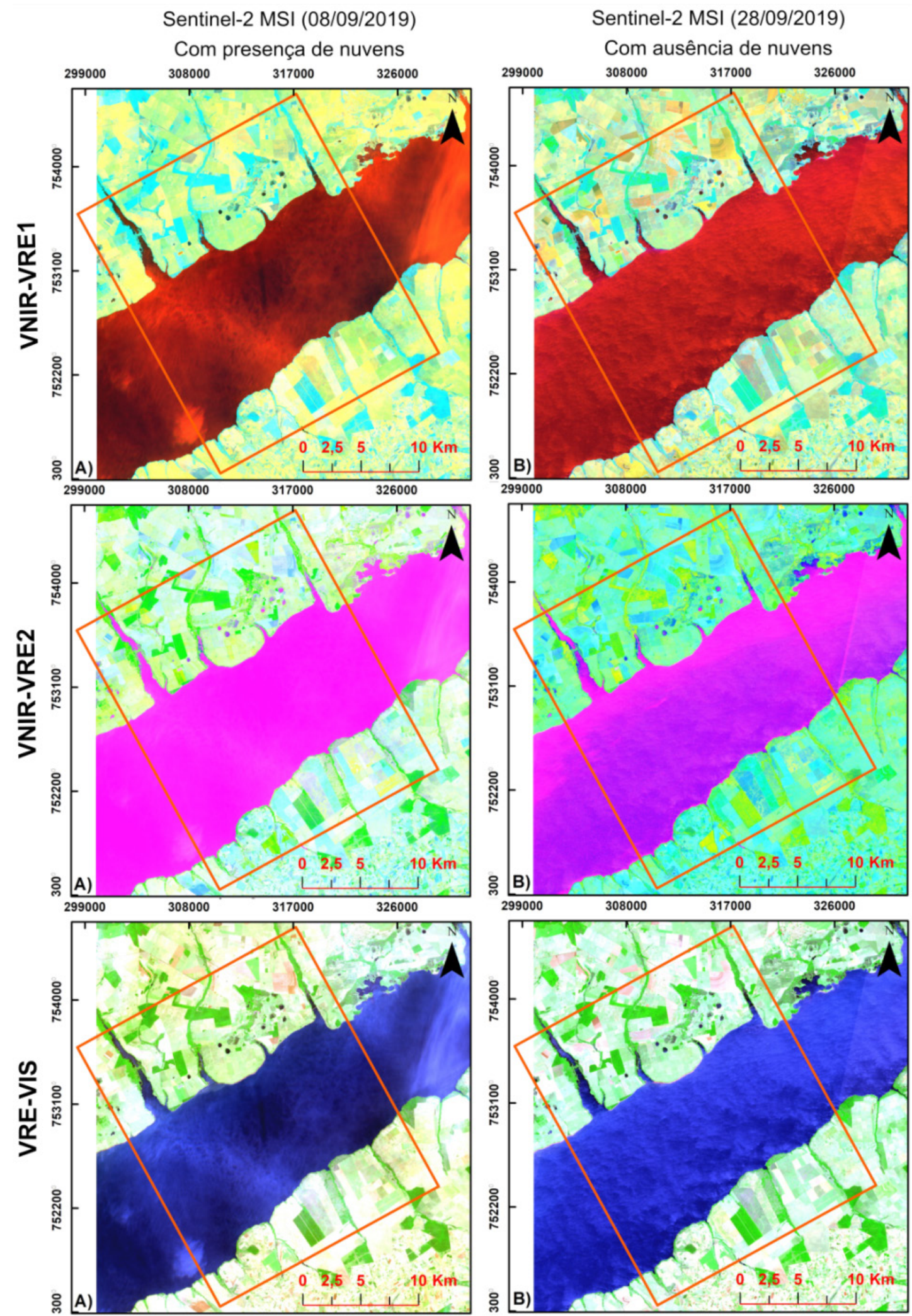

Constata-se que um dos principais fatores que desencadeiam elevado aporte de sedimentos na margem direita (setor sul-matogrossense) está relacionado ao uso agropecuário 
do terreno (Fig. 11), onde o acesso do gado em Áreas de Preservação Permanentes (A) intensificam a compactação do solo, favorecendo a instalação de processos erosivos não relacionados diretamente a ablação derivada do impacto de ondas do reservatório nas margens. Em (B) evidencia-se acesso às margens do córrego Segredo e em (C) o acesso às margens do córrego Fumaça, ambos afluentes da margem direita do rio Paraná. Em (D) observa-se a cicatriz de deslizamento de terra recente em Argissolo vermelho com textura areno-argilosa em decorrência do fatores como desmatamento, pisoteio de gado e provável ascenção do nível piezométrico local, onde o solo sazonalmente tende a se saturar em períodos prolongados de precipitação pluvial, com acumulados em março (Amador, 2017). Na comparação entre imagens do satélite L5 e L8 (Fig. 12), pré-inundação (A) ocorrida em 1998 e pós-inundação (B), destacamos como a APP demarcada entre as linhas rosa e amarela foi afetada com o avanço da linha de costa. Anteriormente a inundação a APP possuia larguras entre 106 a 50 metros (C) e após a inundação a área inundada reduziu de 84 a 9 m a APP (D).

Figura 11: Acessos do gado às Áreas de Preservação Permanente e seu potencial erosivo.

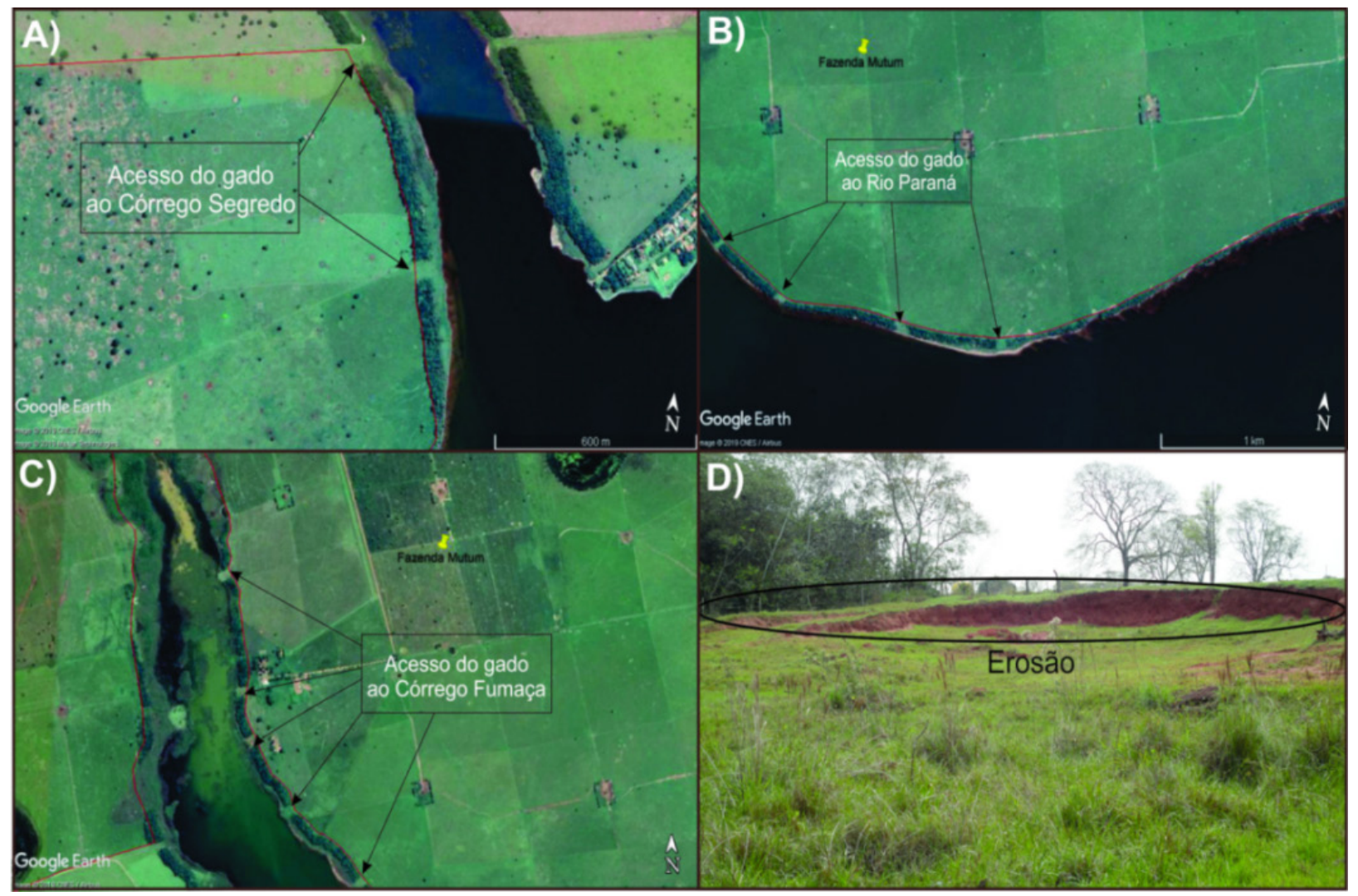


Figura 12: Comparação entre imagens do satélite L5 e L8 pré e pós-inundação em relação às Áreas de Preservação Permamente.
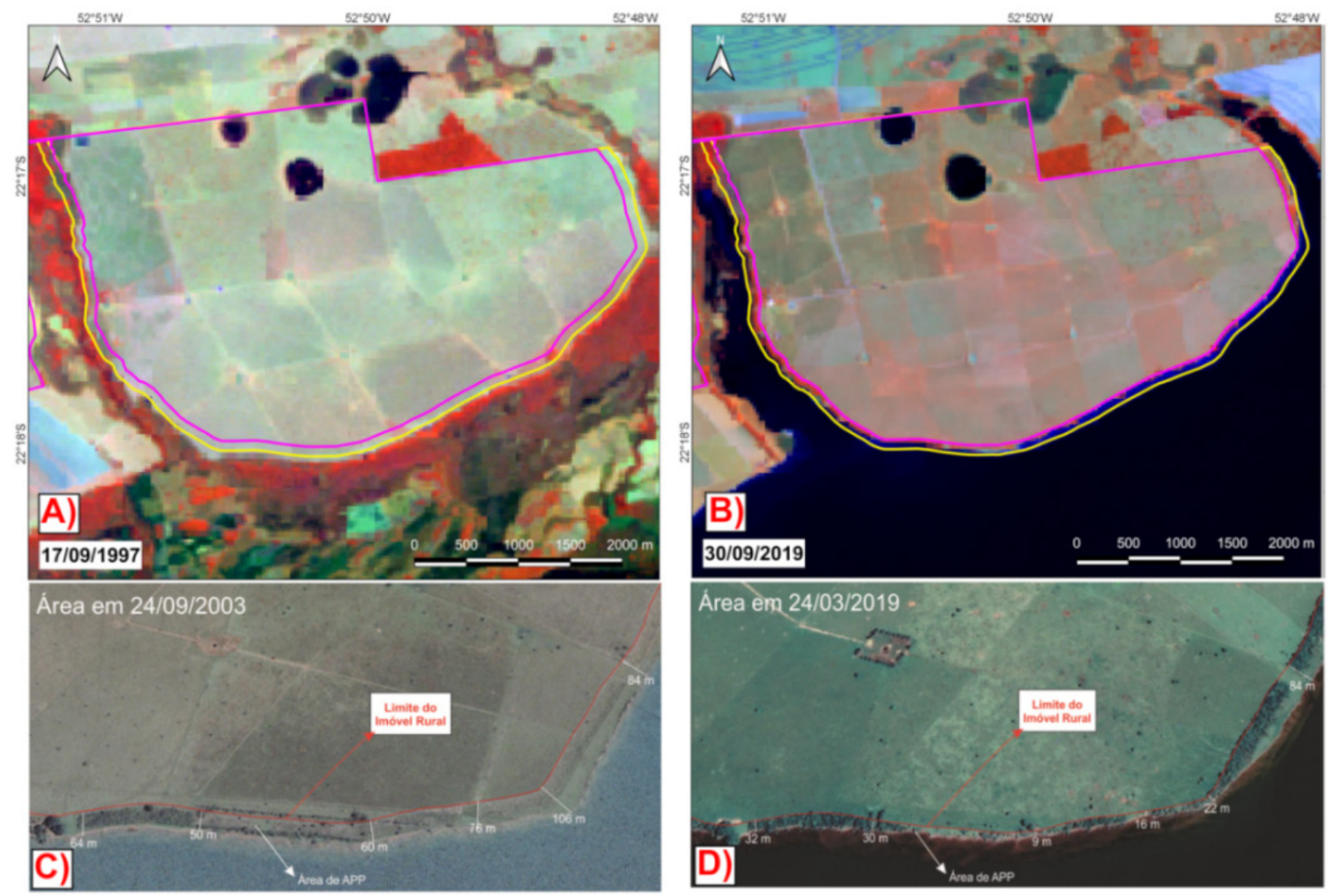

A Figura 13 mostra que a composição cor-verdadeira (RGB:432) realça o transporte de sedimentos oriundo de processos de erosão do material friável das margens impactada pela oscilação de ondas no reservatório (Fig. 13 A). O intervalo de azul claro em comparação ao azul escuro é o que apresenta maior turbidez quando comparado com a imagem de alta resolução obtida pelo RPA (01) no mesmo local. Nesta composição o solo apresenta tons muito variados entre branco e rosado, possivelmente relacionado ao conteúdo relativo entre areia e argila. Quando agrega-se a composição VRE-VIS (Fig. 13 B), consta-se níveis diferenciados de umidade do solo, sendo que nas margens do reservatório (02) e em áreas agricultáveis, há uma faixa ótima de cor em níveis de rosa com tons semelhantes indicando solo exposto. $\mathrm{O}$ teor de umidade provavelmente afeta a tonalidade, sendo que solos mais secos ou bem drenados tendem a apresentar tons de rosa mais claro. 
Figura 13: Comparação entre imagens realçadas por composição de bandas do S2 com imagens de aeronave remotamente pilotada destacando efeitos da erosão marginal no reservatório.

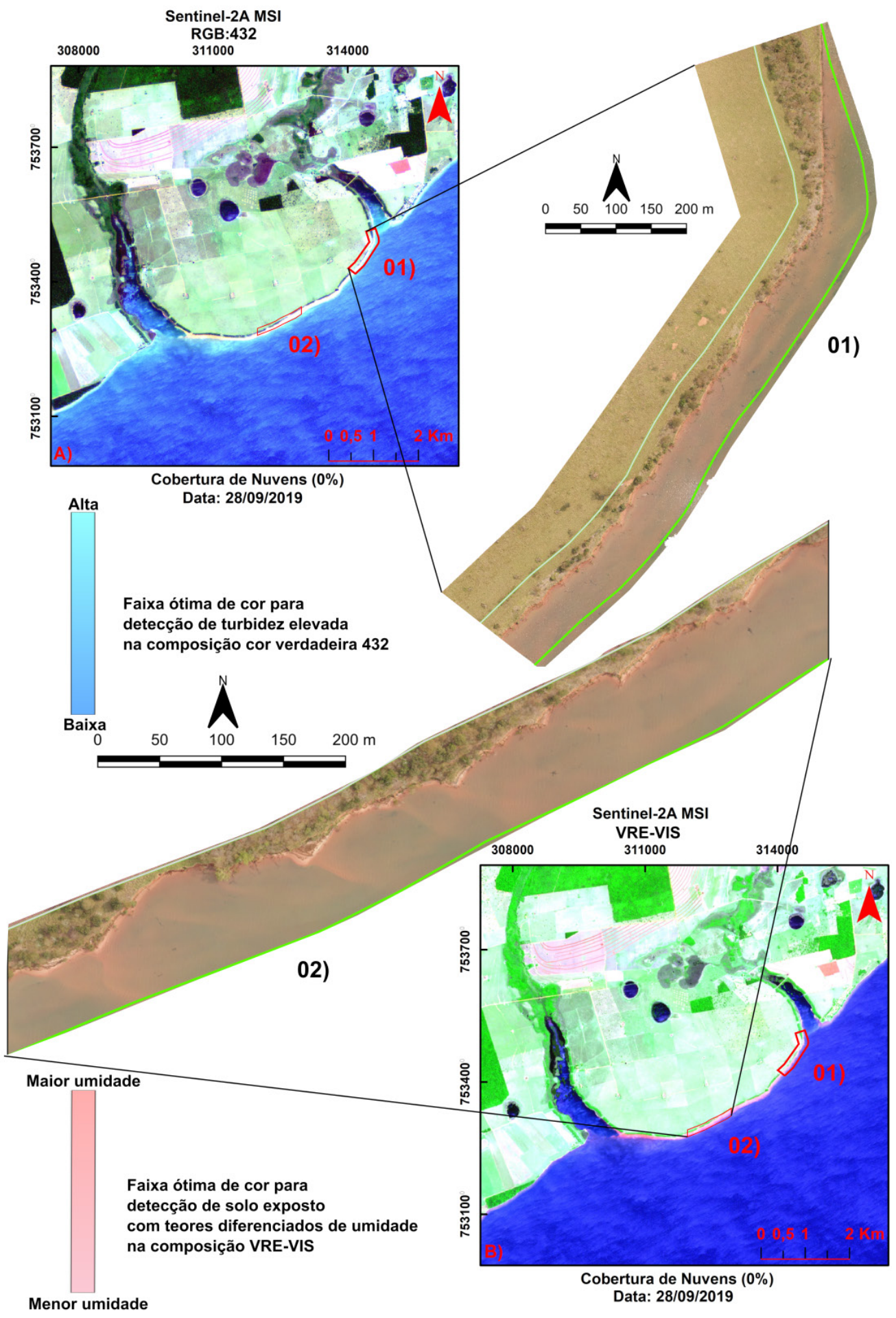

A Figura 14 apresenta o detalhamento das margens inundadas pelo resevatório da UHEESM, onde evidencia-se: (1) Queda de árvores de grande porte; (2) Incisão de sulcos erosivos transversais; (3) Deslizamento de terra associado a solifluxão; (4) Turvação da água devido ao transporte e a elevada carga de material em suspensão oriundo de perda de solo das margens. 
Figura 14: Detalhamento de impactos nas margens inundadas pelo reservatório da UHEESM.
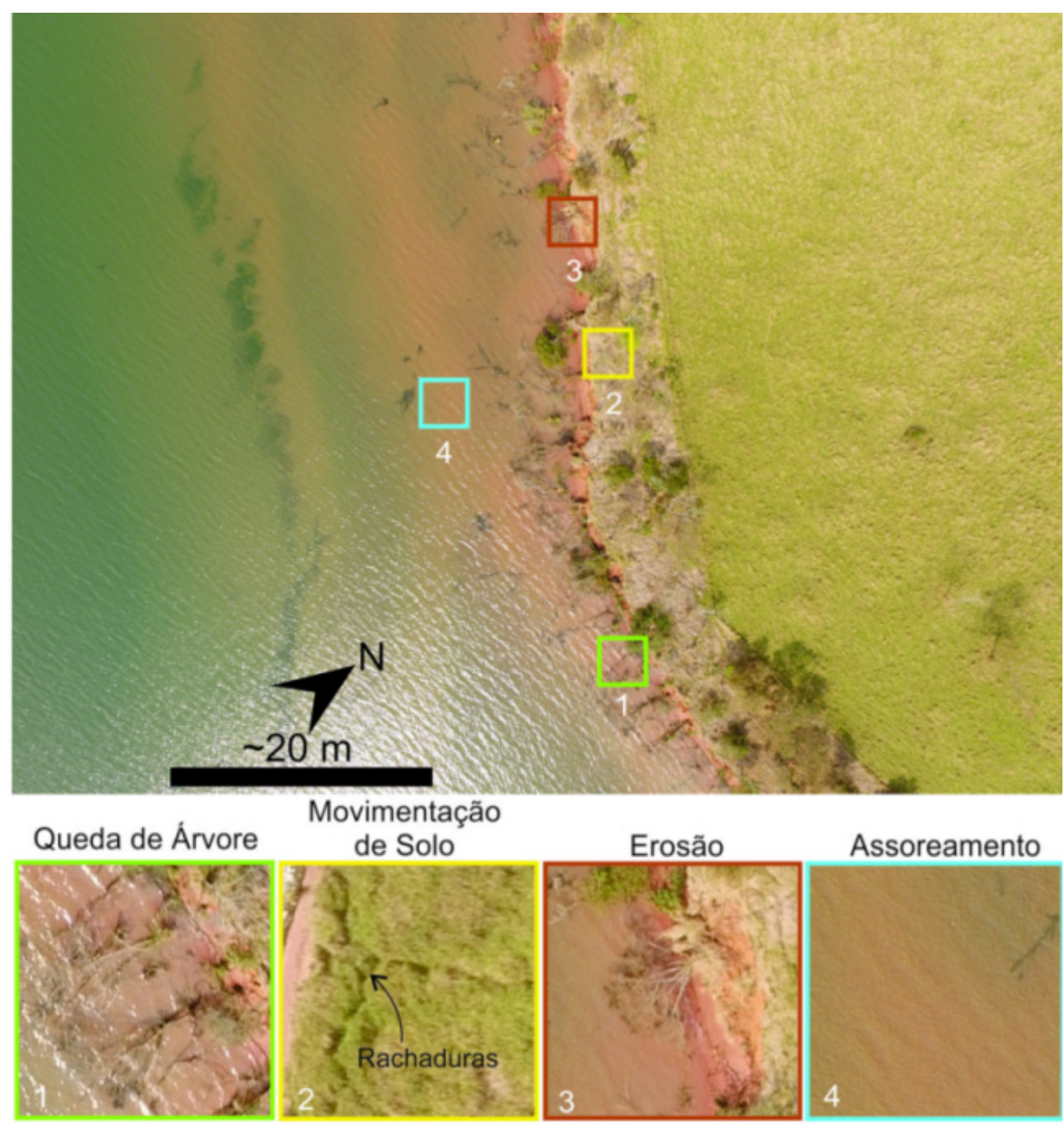

Taxas de erosão podem ser explicadas pelo aumento significativo da vazão e são mais intensas onde o canal principal (talvegue) se aproxima da margem, em que partículas grosseiras do solo diminuem sua resistência ao cisalhamento, e os baixos valores de coesão favorecem excessiva drenagem interna tornando-o mais suscetível à oscilação do nível da água do rio (Rocha, 2009). Somando-se a isto, mudanças no regime hidrológico, cobertura vegetal e gradiente de declive são os principais fatores que governam os padrões espaciais e temporais da erosão do solo na zona de perturbação de flutuação do nível d'água de uma barragem (Bao et al., 2018). A proximidade do canal com o talvegue é uma das principais causas de perdas de solo, as quais estão associadas com meses com maiores valores de vazão, podendo ocorrer também erosão eólica em blocos de solos com perfis expostos (Rocha, Holanda, Rolim, Lino \& Araújo Filho, 2018). A perda por infiltração não deve ser negligenciada para não resultar em superestimação do hidrograma de descarga do reservatório. Além disso, ela pode alterar consideravelmente o tamanho crítico do sedimento do leito, incorporando-o pelo movimento incipiente de fluxo ao transporte de sedimentos com o ajuste morfológico (Ni, Cao, Liu \& Liu, 2020). 
O curso inferior do rio Ivinhema é constituído por uma sequência de blocos de falhas basculadas N-NW formadas por falhas antitéticas rotacionadas, as quais geraram altos estruturais que condicionaram zonas deposicionais em áreas baixas adjacentes (Fortes, Stevaux \& Volkmer, 2005). Este modelo condiz com os dados obtidos neste estudo, onde também é observado o entalhamento assimétrico dos vales, formando uma depressão que repercute em leques aluviais depositados preferencialmente na margem direita numa zona de mistura com colúvio oriundo da parte terrestre marginal erodida, favorecendo maior aporte de material inconsolidado na margem esquerda.

O conjunto de áreas analisadas denota uma considerável variabilidade quanto às taxas de erosão marginal ao longo do reservatório. Genericamente, a margem esquerda é menos afetada por processos erosivos, mesmo possuindo declividades altas, uma vez que está estabilizada pelo substrato rochoso aflorante em compartimentos de relevo escarpado e menos favorável a formação de perfis espessos de solo. Porém este setor é suscetível a eventos de tombamento de terra quando há geralmente Neossolos. Já a margem direita é menos estável devido à presença de perfis de solos mais espessos, onde leques aluvionares são retrabalhados por ondas, aumentando a turbidez e consequentemente a quantidade de sólidos totais em suspensão (Fig. 15). A maior taxa relativa de erosão nesta margem é influenciada pelo aumento relativo da vazão, tendo em vista que a área total de decantação e a profundidade do canal são menores, conforme aferido indiretamente pela composição VNIR-VRE2, sendo a rugosidade e a geometria do canal fatores que induzem essa variação. Mesmo nas margens vegetadas e com solos argilosos, o contato direto com a água do rio vem favorecendo a incidência de escorregamentos de terra com a evolução de cicatrizes e sulcos erosivos, sendo comum o tombamento de árvores na faixa de APP.

Há possibilidade de ocorrência de pipping ou processos de carstificação sendo induzidos com a subida do nível freático, porém será necessária a aplicação de métodos geofísicos de investigação aliados a mapeamentos geológicos de maior detalhe para confirmar esta hipótese. A frequente transferência de energia no regime fluvial controlado por barragem opera ciclos de erosão e deposição constantes, extremamente dinâmicos e complexos. Com as operações da barragem, o nível d'água oscila diariamente, favorecendo a elevação do nível freático e o aumento do fluxo das águas subterrâneas, tanto nas ilhas quanto nas margens (Stevaux, Martins \& Meurer, 2009). Há combinação de dois vetores principais de dissipação da energia das ondas, guiadas de montante para jusante no sentindo natural do fluxo e da margem esquerda para direita, provavelmente induzida pala operação dos reservatórios da margem direita (setor paulista). 
Figura 15: Síntese dos impactos na zona de perturbação de barragem no reservatório da UHEESM (perfil $\mathrm{AA}^{\prime}$ com escala exagerada).

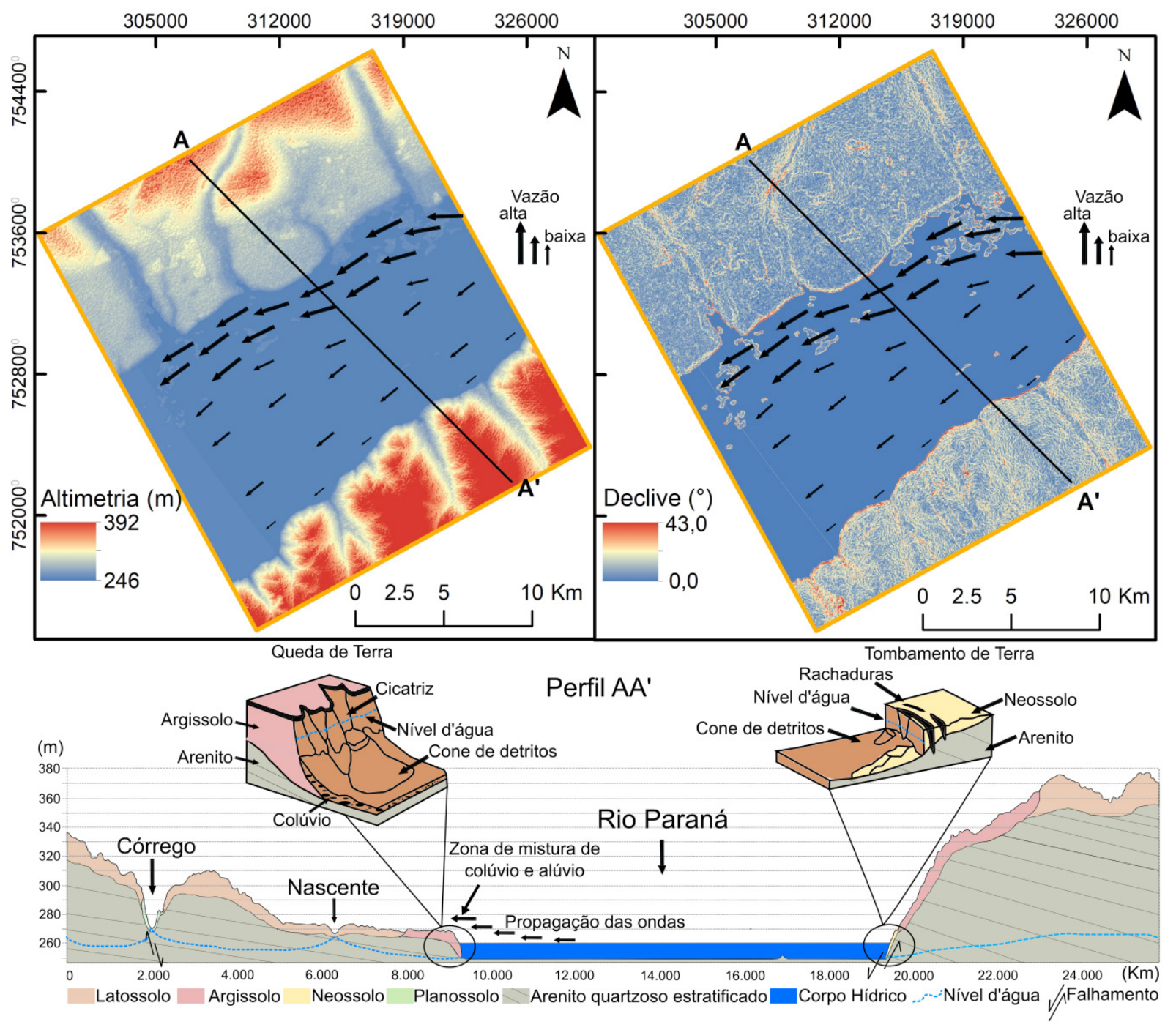

Atualmente há pouco conhecimento do impacto do represamento da água na erosão do solo, considerando séries temporais longas (acima de 30 anos). Monitorar, e modelar os processos atuantes que controlam o fluxo de entrada e saída de sedimentos, considerando a perda de solo nas bacias hidrográficas adjacentes, bem como o desenvolvimento de técnicas de amostragem contemplando o uso de geotecnologias servirão na tomada de decisões relativas à manutenção da barragem e seu ecossistema. Rotinas de processamento digital de imagens no Google Earth Engine (Gorelick, Hancher, Dixon, Ilyuschenko, Thau \& Moore, 2017) e aplicações de contrastes com redução da dimensionalidade da imagem, tal como a análise de componentes principais poderão sem implementadas para suprir essa lacuna do conhecimento nos reservatórios tropicais brasileiros. 


\section{CONCLUSÃO}

As técnicas de realce baseada em combinação simples e por equação de bandas multiespectrais são capazes de discernir, macroscopicamente, variações no ambiente hídrico. A utilização de múltiplas fontes de imagens, tanto na comparação entre séries temporais, quanto na identificação de impactos na zona de perturbação de barragem realizada em escalas progressivas, foi essencial para um diagnóstico holístico dos fenômenos. A combinação 432 no S2 juntamente com a combinação VRE-VIS, adaptada neste estudo, fornecem situações diagnósticas de erosões marginais ativas, uma vez que, a primeira realça sedimentos em suspensão e a segunda o solo exposto nas margens ou submerso por pequena coluna d'água. Já para destacar a profundidade da lâmina d'água indicamos a composição VNIR-VRE2, pois ela apresenta maior nitidez comparada às demais combinações realizadas. Processos erosivos marginais ativos detectados por RPA demonstram-se eficientes para diagnósticos que necessitam de maior detalhamento e compreensão do nível de severidade do dano ambiental.

A zona de impacto da barragem possui tanto fatores naturais, quanto antrópicos que induzem conjuntamente e em escalas diferentes a incidência e evolução de movimentos de massa com perdas de solo significativas e constantes para o corpo hídrico. Nesse contexto, as geotecnologias são ferramentas auxiliares com alto potencial a ser explorado para identificar e priorizar tomadas de decisões que visem estabilizar áreas marginais afetadas pela dinâmica de flutuação do nível d’água dos reservatórios.

\section{AGRADECIMENTOS}

Os autores agradecem ao PGTA/UFMS (Programa de Pós-Graduação em Tecnologias Ambientais), da Universidade Federal de Mato Grosso do Sul - UFMS. Esta pesquisa foi realizada com apoio da Coordenação de Aperfeiçoamento de Pessoal de Nível Superior (CAPES), CNPq (Conselho Nacional de Desenvolvimento Científico e Tecnológico, Processo 1815261/2019-01 de bolsa de doutorado; Processo 305013/2018-1 de bolsa de produtividade em pesquisa) e Fundação Universidade Federal de Mato Grosso do Sul - UFMS/MEC..

\section{REFERÊNCIAS}

Agência Nacional de Águas (2014). Acervo educacional sobre água: Qualidade de Água em Reservatórios. Brasília. (Unidade 1: Reservatórios). Recuperado de https://capacitacao.ana.gov.br/conhecerh/ browse?type $=$ dateissued.

Agência Nacional de Águas (2020). HidroWeb: Sistemas de Informações Hidrológicas. Recuperado de http:// www.snirh.gov.br/hidrotelemetria/Mapa.aspx

Alaska Satellite Facility (2010). Imagem de Satelite ALOS-1 (Advanced Land Observing Satellite) PALSAR (Phased Array L-band Synthetic Aperture Radar) - JAXA Japan Aerospace Exploration Agency. Modo FBD (Fine Beam Dual polarization: $H H+H V$ ou $V V+V H)$. Recuperado de https://vertex.daac.asf.alaska.edu/ 
Amador, Maisa C. (2017). Variabilidade e regime das chuvas na Unidade de Planejamento e Gerenciamento Ivinhema no período de 1980 a 2010. (Dissertação de Mestrado em Geografia). Universidade Federal da Grande Dourados, UFGD, Dourados, MS, Brasil. Recuperado de http://repositorio.ufgd.edu.br/jspui/ handle/prefix/1246

Arai, Fabiane K. (2010). Caracterização da disponibilidade hídrica na Bacia Hidrográfica do Ivinhema, MS. (Dissertação de Mestrado em Agronomia). Universidade Federal da Grande Dourados, UFGD, Dourados, MS, Brasil. Recuperado de http://repositorio.ufgd.edu.br/jspui/handle/prefix/298

Araújo, Silvânia H., Furrier, Max, \& Monteiro, Gabriel N. (2016). Geoprocessamento aplicado à análise de assoreamento e erosão fluvial em reservatório: estudo de caso dos reservatórios Gramame-Mamauba - PB. Geo UERJ, 29:473-490. https:/ / doi.org/10.12957/geouerj.2016.22180

Bao, Yuhai, He, Xiubin, Wen, Anbang, Gao, Peng, Tang, Qiang, ... \& Long, Yi (2018). Dynamic changes of soil erosion in a typical disturbance zone of China's Three Gorges Reservoir. Catena, 169:128-139. https:// doi.org/10.1016/j.catena.2018.05.032

Bataghin, Fernando A., Gonçalves, Marcelino A., Ikuta, Flávia A. et al. (2017). Comitê de bacia hidrográfica do rio Ivinhema - MS: Origens e desafios para atuação na área de resíduos. Congresso Brasileiro de Gestão Ambiental, Campo Grande, MS, Brasil, 8. (pp. 1-6). Recuperado de https:/ /www.ibeas.org.br/congresso/ Trabalhos2017/III-004.pdf

Caballero, Isabel, Stumpf, Richard P., \& Meredith, A. (2019). Preliminary assessment of turbidity and chlorophyll impacto $n$ bathymetry derived from Sentinel-2A and Sentinel-3A satellites in South Florida. Remote Sensing, 11(645):1-20. https:// doi.org/10.3390/rs11060645

Coelho, André L.N. (2008). Geomorfologia fluvial de rios impactados por barragens. Caminhos da Geografia, 9(26):16-32. Recuperado de http://www.seer.ufu.br/index.php/caminhosdegeografia/article/ view/15721

Coelho, André L.N., \& Cunha, L. (2019). Análise da intensidade e das áreas de erosão marginal no médio-baixo rio Doce (ES). Simpósio Brasileiro de Geografia Física Aplicada. Fortaleza, CE, Brasil, 17. (pp. 1-12). Recuperado de http://www.editora.ufc.br/images/imagens/pdf/geografia-fisica-e-as-mudancasglobais/289.pdf

Environmental Systems Research Institute (2013). ArcGIS Desktop, 10.2.1. Redlands.

Fachin, Viviane S. (2016). Reordenamento de terras no Mato Grosso do Sul. Revista de Ciências Sociais, 45:4766. Recuperado de https:// periodicos.ufpb.br/ojs/index.php/politicaetrabalho/article/view/30636

Feyisa, Gudina L., Meilby, Henrik, Fensholt, Rasmus, \& Orgulhoso, Simon R. (2014). Automated Water Extraction Index: A new technique for surface water mapping using Landsat imagery. Remote Sensing of Environment, 140:23-35. https://doi.org/10.1016/j.rse.2013.08.029

Fortes, E, Stevaux, José C, \& Volkmer, Sérgio (2005). Neotectonics and channel evolution of the Lower Ivinhema River: A right-bank tributary of the upper Paraná River, Brazil. Geomorphology, 70:325-338. https:// doi.org/10.1016/j.geomorph.2005.02.011

Franco, Rodolfo (2017). Composiciones Landsat em ArcGis. Guía Básica. Bogotá. Recuperado de https:// mixdyr.wordpress.com/2017/06/30/composiciones-landsat-en-arcgis/.

García-García, Fernando, Sánchez-Gomez, Mario, Navarro, Vicente, \& Pla, Sila (2011). Formation, infill, and dissection of a latest-Pleistocene landslide-dammed reservoir (Betic Cordillera, Southern Spain): Upstream and downstream geomorphological and sedimentological evidence. Quaternary International, 233(1):61-71. https:// doi.org/10.1016/j.quaint.2010.07.010

Gorelick, Noel, Hancher, Matt, Dixon, Mike, Ilyuschenko, Simon, Thau, David, \& Moore, Rebecca (2017). Google Earth Engine: Planetary-scale geospatial analysis for everyone. Remote Sensing, 202(1):18-27. http:// dx.doi.org/10.1016/j.rse.2017.06.031

Instituto de Meio Ambiente de Mato Grosso do Sul (2015). Plano de Recursos Hídricos da Bacia Hidrográfica do Rio Ivinhema. Campo Grande (Versão Final). Recuperado de https:/ / www.imasul.ms.gov.br/plano-derecursos-hidricos-rio-ivinhema-2/ 
Lima, Diego L., Motta, Jaíza S., Souza, Camila A., Guirra, Alesson P.M., \& Paranhos Filho, Antonio C. (2019). Revisão bibliométrica sobre turbidez e sólidos suspensos por sensoriamento remoto. Anuário do Instituto de Geociências, 42(1):107-116. http:/ / dx.doi.org/10.11137/2019_1_107_116

McFeeters, Stuart K. (1996). The use of the Normalized Difference Water Index (NDWI) in the delineation of open water features. International Journal of Remote Sensing, 17(7):1425-1432. http:/ / dx.doi. org/10.1080/01431169608948714

$\mathrm{Ni}$, Yufang, Cao, Zhixian, Liu, Qing, \& Liu, Qingquan (2020). A 2D hydrodynamic model for shallow water flows with significant infiltration losses. Hydrological Processes, 34(10):2263-2280. https:// doi.org/10.1002/ hyp.13722

Oliveira, Wallace (2004). Os impactos ambientais motivados pela UHE Porto Primavera no município de Anaurilândia - MS. de (Tese de Doutorado em Geografia). Universidade Estadual Paulista, UNESP, Presidente Prudente, SP, Brasil. Recuperado de https:/ / repositorio.unesp.br/handle/11449/101437

Pepe, Thiago A.P., \& Berezuk, André G. (2013). Recursos hídricos e a dinâmica produtiva da bacia hidrográfica do rio Ivinhema - MS. Simpósio Brasileiro de Recursos Hídricos, Bento Gonçalves, RS, Brasil, 20. (pp. 1-8).

Pott, Arnildo, Silva, João dos S.V., \& Gomes, Edmur L. (2014). Características da bacia hidrográfica do rio Ivinhema. Revista GeoPantanal, 16:109-124. Recuperado de https:/ / periodicos.ufms.br/index.php/revgeo/ article/view/366

Rocha, Igor P. (2009). Relação entre a erosão marginal, atributos físicos do solo e variáveis hidrológicas e climáticas no baixo São Francisco sergipano. (Dissertação de Mestrado em Agrossistemas). Universidade Federal de Sergipe, UFS, São Cristóvão, SE. Recuperado de https:/ / bdtd.ibict.br/vufind/Record/UFS-2_204f512734 696153f362932f6f842e50

Rocha, Igor P., Holanda, Francisco S.R., Rolim, Mario M., Lino, Janisson B., \& Araújo Filho, Renisson N. (2018). Magnitude and spatiotemporal variation of the erosion on the slope of the lower São Francisco river, northeastern Brazil. Jornal of Experimental Agriculture International, 24(1):1-11. https://doi.org/10.9734/ JEAI/2018/41944

Rosa, Jota J.M., Ferreira, Djane da S., \& Rosa, João R. (2018). O fomento Terra Prometida no sul de Mato Grosso (1930-1950). Geo UERJ, 32:1-26. https:/ / doi.org/10.12957/ geouerj.2018.23672

Serviço Geológico do Brasil (2006a). Geologia e Recursos Minerais do Estado de Mato Grosso do Sul (Texto Explicativo). Campo Grande. Recuperado de http://rigeo.cprm.gov.br/xmlui/handle/ doc/10217?show $=$ full

Serviço Geológico do Brasil (2006b). Mapa Geológico do Estado do Mato Grosso do Sul (1:1.000.000). Campo Grande. Recuperado de http://rigeo.cprm.gov.br/xmlui/handle/doc/10217?show=full

Serviço Geológico do Brasil (2009). Mapa Geodiversidade de Mato Grosso do Sul (1:1.000.000). Campo Grande. Recuperado de http://rigeo.cprm.gov.br/xmlui/handle/doc/10217?show=full

Shiroma, Gustavo M., Gamarra, Roberto M., Guirra, Alesson P. M., Motta, Jaíza S., Figueiredo, Helen R., Encina, Paulo C.C. ... \& Paranhos Filho, Antonio C. (2020). Comparação entre índices de vegetação de diferentes sensores na identificação de fitofisionomias do Cerrado. Anuário do Instituto de Geociências, 43(1):18-32, 2020. http://dx.doi.org/10.11137/2020_1_18_32

Teodoro, Paulo E., Oliveira-Júnior, José F., Cunha, Elias R., Correa, Caio C.G., Torres, Francisco E., ... \& Ribeiro, Larissa P. (2016). Cluster analysis applied to the spatial and temporal variability of monthly rainfall in Mato Grosso do Sul State, Brazil. Meteorology and Atmospheric Physics, 128(2):197-209. https:// doi.org/10.1007/s00703-015-0408-y

Runge, Alexandra, \& Grosse, Guido (2019). Comparing Spectral Characteristic of Landsat-8 and Sentinel Same-Day for Artic-Boreal Regions. Remote Sensing, 11(1730): 1-29. https:/ / doi.org/10.3390/rs11141730

Santos, Jeater W.M.C., Loverde-Oliveira, Simoni, Angeoletto, Fabio (2016). Diagnóstico socio-ambiental de las áreas de preservación permanente del rio Arareau en la zona urbana de Rondonópolis. Terr@ Plural, 10(1):35-45. https:// doi.org/ 10.5212/TerraPlural.v.10i1.0003 
Secretaria de Planejamento e Coordenação Geral (1988). Projeto Estudos Integrados do Potencial de Recursos Naturais - Solos (1:1.000.000). Campo Grande.

Stevaux, José C., \& Latrubesse, Edgardo M. (2017).Geomorfologia fluvial. São Paulo: Oficina de Textos,

Stevaux, José C., Martins, Débora P., \& Meurer, M. (2009). Changes in a large regulated tropical river: The Paraná River downstream from the Porto Primavera Dam, Brazil. Geomorphology, 113(1): 230-238. https:// doi.org/10.1016/j.geomorph.2009.03.015

Teixeira, Jodenir C., \& Hespanhol, Antonio N. (2012). A expansão canavieira na bacia do rio Ivinhema no estado de Mato Grosso do Sul. Encontro Nacional de Geografia Agrária, Uberlândia, MG, Brasil, 21. (pp. 1-16). Recuperado de http://www.lagea.ig.ufu.br/xx1enga/anais_enga_2012/eixos/1169_1.pdf

Tommaselli, Antonio M.G., Moraes, Marcus V.A., Silva, Lara S.L., Rubio, M.F., Carvalho, G.J., \& Tommaselli, J.T.G. (2014). Monitoring marginal erosion in hydroelectric reservoirs with terrestrial mobile laser scanner. International Archives of the Photogrammetry, Remote Sensing and Spatial Information Sciences, p. 589-596. https:/ / doi:10.5194/isprsarchives-XL-5-589-2014

United States Geological Survey. (2020a). EarthExplorer. Washington, DC. Recuperado de https:// earthexplorer.usgs.gov/

United States Geological Survey (2020b). USGS EROS Archive - Sentinel-2 - Comparison of Sentinel-2 and Landsat. Washington, DC. Recuperado de https://web.archive.org/web/20170515022022/https:// landsat.gsfc.nasa.gov/wp-content/uploads/2015/06/Landsat.v.Sentinel-2.png.

Volkmer, Sérgio A.J. (2020). Selective Enhancement based on Indices. Git Hub Repository. Porto Alegre. Recuperado de https://github.com/smaprs/sel_enh_index/blob/master/script.js

Wang, Zifeng, Liu, Junguo, Li, Jinbao et al. (2018). Multi-Spectral Water Index (MuWI): A native 10-m multispectral water index for accurate water mapping on Sentinel-2. Remote Sensing, 10(1643):1-21. https://doi. org/10.3390/rs10101643

Data de submissão: 02/jun./2020

Data de aceite: $17 /$ ago./2020 